\title{
Preparation and Activity of Small Rhodium Metal Particles on Fishbone Carbon Nanofibres
}

\author{
T. G. Ros, D. E. Keller, A. J. van Dillen, J. W. Geus, and D. C. Koningsberger ${ }^{1}$ \\ Department of Inorganic Chemistry and Catalysis, Debye Institute, Utrecht University, P.O. Box 80083, 3508 TB Utrecht, The Netherlands
}

Received February 7, 2002; revised May 23, 2002; accepted May 23, 2002

\begin{abstract}
A number of different impregnation and ion-exchange procedures have been employed to synthesize very small rhodium metal particles on $\mathrm{HNO}_{3} / \mathrm{H}_{2} \mathrm{SO}_{4}$-oxidized fishbone carbon nanofibres. The surface-oxidation of the nanofibres with $\mathrm{HNO}_{3} / \mathrm{H}_{2} \mathrm{SO}_{4}$ is a prerequisite for a good interaction between aqueous catalyst precursor solutions and the fibres. Depending upon the preparation technique applied and using $1 \mathrm{wt} \%$ rhodium metal loadings average particle sizes ranging from 1.1 to $2.1 \mathrm{~nm}$ were detected with XAFS spectroscopy. The rhodium metal particles are so small that metalsupport interactions on carbon nanofibres can be investigated with XAFS spectroscopy. All catalysts are highly active in the liquidphase hydrogenation of cyclohexene. No significant effect of particle size on the catalytic activity is observed, suggesting that other factors, such as clustering of the support particles in the liquid phase, are much more important. (c) 2002 Elsevier Science (USA)
\end{abstract}

Key Words: carbon nanofibres; EXAFS spectroscopy; heterogeneous catalysis; hydrogenation; rhodium metal particles.

\section{INTRODUCTION}

Currently, there is much interest in the physical and chemical properties of carbon nanotubes and carbon nanofibres (CNFs). Whereas carbon nanotubes are usually synthesized by arc discharge techniques, CNFs are obtained by catalytic decomposition of carbon-containing gases on small supported metal particles. The arc discharge technique can produce carbon nanotubes only in small quantities. Furthermore, thus-produced tubes are polluted with other forms of carbon, such as carbon onions, fullerenes, or amorphous carbon. Carbon nanofibres, on the other hand, do not contain other forms of carbon. Additionally, no heteroatoms, such as sulphur, are incorporated during synthesis. The metal and support of the catalyst originally used to grow the CNFs, however, have to be removed after synthesis. Investigation of use of carbon nanotubes and carbon nanofibres as catalyst support has only started recently (1-15). Carbon nanotubes are mostly used to study the effects of this novel carbon material on the properties of the final supported catalyst. The arc discharge proce-

\footnotetext{
${ }^{1}$ To whom correspondence should be addressed. Fax: 030-2511027. E-mail: D.C.Koningsberger@chem.uu.nl.
}

dure, however, is too expensive to envisage thus-produced carbon nanotubes as a support on a commercial scale. Carbon nanofibres, on the other hand, are a promising catalyst support material. The perspective is that when grown in a fluidised bed reactor, carbon nanofibres can be obtained at low cost, making commercial application possible (1). The properties of CNFs make them especially suitable for liquid-phase reactions. The fibres are mechanically strong and can withstand the forces involved in vigorous agitation of the reaction medium. Furthermore, the skeins of fibres possess a mesoporous macrostructure, which decreases the possibility of encountering diffusion limitations during catalytic reactions in the liquid phase with respect to microporous materials, such as activated carbon. The structure of the CNFs can be tuned by changing the growth conditions and their hydrophobicity can be controlled by surface oxidation. The fibres are chemically inert and can be used in strongly acidic or basic liquids. Finally, after deactivation of the catalyst, CNFs can be readiliy combusted to recover the precious metal component of spent catalysts without leaving ash residues.

The use of carbon nanofibres and nanotubes as catalyst support has been reviewed recently (1). A strong incentive for their use is the replacement of activated carbon (AC) for liquid-phase reactions. The properties of ACs are difficult to control. Unsatisfactory reproducibility as well as the microporosity of activated carbon has often impeded catalyst development. The sometimes inadequate mechanical properties of AC may lead to filtration problems in liquid-phase applications.

Hoogenraad and co-workers (2-6) extensively studied the use of $\mathrm{Pd} / \mathrm{CNF}$ for the hydrogenation of nitrobenzene to aniline. The authors prepared fibres with the graphite layers parallel to the fibre axis (parallel fibres) and fibres with the graphite layers at an angle with the fibre axis (fishbone fibres). The smallest $\mathrm{Pd}$ particles were obtained when fibres that were oxidized with $\mathrm{HNO}_{3}$ were ion exchanged with a positively charged $\mathrm{Pd}$-ammonia complex under the exclusion or air. With parallel fibres a maximal loading of $3 \mathrm{wt} \%$ was obtained, while with fishbone fibres only $1.5 \mathrm{wt} \%$ $\mathrm{Pd}$ could be exchanged (3). On parallel fibres Pd particles of about $1.5 \mathrm{~nm}$ were obtained (6). The $\mathrm{Pd} / \mathrm{CNF}$ catalyst 
turned out to be more active than a $\mathrm{Pd} / \mathrm{AC}$ catalyst of a higher metal loading (2). Though the authors did not offer an explanation for the higher activity of the fibre-supported catalyst, an effect of the size or the clustering of the carbon support bodies is very likely.

Baker and co-workers studied the activity of several metals on $\mathrm{CNFs}$. $\mathrm{Fe}$ or $\mathrm{FeCu}$ precursors were impregnated on $\mathrm{HCl}$-treated CNFs, ultimately resulting in particles of an average size of $12 \mathrm{~nm}$ at $5 \mathrm{wt} \%$ loading (7). In spite of the relatively large size of the metal crystallites, the activity of these catalysts was considerably higher in the hydrogenation of ethylene than $\mathrm{Fe}(\mathrm{Cu})$ was on activated carbon or alumina. The authors pointed out the possible relationship between this activity enhancement and a unique metalsupport interaction between the metal particles and the basal planes of the fibres. In later publications (8-10), Ni was impregnated on CNFs, resulting in 6- to 8-nm-size particles. Again, activity improvement compared to that of nickel metal on classical supports was obtained in the hydrogenation of 1-butene and 1,3-butadiene (8). Furthermore, differently structured carbon nanofibres displayed different activities and selectivities (9). Preferential blocking of either the armchair or the zigzag graphitic edge faces with $\mathrm{P}$ or $\mathrm{B}$, respectively, indicated that the effects could be ascribed to the catalytic action of Ni residing on the zigzag faces (10). Similar effects were found when the hydrogenation of crotonaldehyde on $\mathrm{Ni} / \mathrm{CNF}$ was studied (11). The nanofibre-supported catalysts were more active than $\mathrm{Ni} / \mathrm{Al}_{2} \mathrm{O}_{3}$. Moreover, when alumina or "ribbon" CNFs were used as the supports, selective hydrogenation of the double bond took place, whereas with "platelet" CNFs the aldehyde functional group was converted. The results were related to the adsorption of crotonaldehyde on nickel particles on the zigzag faces, which supposedly have a special atomic arrangement.

Other researchers found surprising selectivities in selective hydrogenation reactions as well. Ledoux and coworkers (12) impregnated Pd on acid-treated CNFs and obtained 3- to 5-nm-size particles at $5 \mathrm{wt} \%$ loading. A very high activity and a $98 \%$ selectivity towards the aldehyde was found with the hydrogenation of cinnamaldehyde at atmospheric pressure and $80^{\circ} \mathrm{C}$. Planeix et al. (13), on the other hand, observed a selectivity towards cinnamyl alcohol of $92 \%$ with 3- to 7-nm-size Ru particles on nonpurified nanotubes (0.2 wt \% loading).

Finally, it is worth mentioning the work of Ang et al. (14) and of Keyser and Prinsloo (15). Ang deposited 2-nm-size $\mathrm{Pd}$ particles on $\mathrm{HNO}_{3} / \mathrm{H}_{2} \mathrm{SO}_{4}$-oxidized carbon nanotubes by using an electroless plating technique. He reported that the tubes were densely coated with particles, indicating a high metal loading. Prinsloo used deposition-precipitation from a homogeneous solution to obtain $\mathrm{HNO}_{3}$-oxidized carbon nanofibres densely coated with cobalt particles of 7-nm diameter.
This work describes the deposition of small rhodium metal particles on fishbone carbon nanofibres by several impregnation and ion-exchange techniques. The objective is to assess which fibre pretreatment procedures are needed to achieve an optimal interaction of the nanofibres with the catalyst precursor. Very small (1-2 nm) metal particles can be deposited on surface-oxidized CNFs. Furthermore, the influence of calcination and reduction procedures on the final metal particle size is studied. The size of the particles provides the opportunity to study metal-support interactions with XAFS spectroscopy, which requires very small particles and a narrow particle size distribution. These studies could shed more light on the unusual activities and selectivities described above. The Rh/CNF catalysts were tested in the liquid-phase hydrogenation of cyclohexene. Very high activities were found. Moreover, the results might indicate that other factors, such as clustering of the catalyst support particles in the liquid phase, are more important in determining the activity of the catalyst than is metal particle size.

\section{EXPERIMENTAL}

\subsection{Growth of Fishbone Carbon Nanofibres}

Carbon nanofibres of the fishbone type were produced by catalytic decomposition of $\mathrm{CH}_{4}$ on a Ni/ $\mathrm{Al}_{2} \mathrm{O}_{3}$ catalyst $(2-4,16)$.

The $\mathrm{Ni} / \mathrm{Al}_{2} \mathrm{O}_{3}$ catalyst with $30 \mathrm{wt} \% \mathrm{Ni}$ metal loading was synthesized by the deposition-precipitation technique (17). Alumina (Alon-C, Degussa) was suspended in an acidified aqueous solution of nickel nitrate (Acros, 99\%) and diluted ammonia was injected within $2 \mathrm{~h}$ at room temperature under vigorous stirring until the $\mathrm{pH}$ had reached a value of 8.5. After overnight stirring, the suspension was filtered, washed, and dried at $120^{\circ} \mathrm{C}$. Finally, the catalyst was calcined at $600^{\circ} \mathrm{C}$ in stagnant air for $3 \mathrm{~h}$.

For the production of fishbone CNFs, $0.5 \mathrm{~g}$ of the $30 \mathrm{wt} \%$ $\mathrm{Ni} / \mathrm{Al}_{2} \mathrm{O}_{3}$ catalyst was reduced at $600^{\circ} \mathrm{C}$ in $14 \% \mathrm{H}_{2}$ in $\mathrm{N}_{2}$ (flow rate, $350 \mathrm{ml} / \mathrm{min}$ ) in a vertical tubular reactor (diameter, $3 \mathrm{~cm}$ ) for $2 \mathrm{~h}$. After the temperature was decreased to $570^{\circ} \mathrm{C}$, methane $\left(50 \%\right.$ in $\mathrm{N}_{2}$, flow rate of $\left.450 \mathrm{ml} / \mathrm{min}\right)$ was passed through the catalyst bed for $6.5 \mathrm{~h}$. The yield of fibres amounted to approximately $12 \mathrm{~g}$.

The synthesis of the fishbone CNFs was confirmed with high-resolution TEM (18).

\subsection{Catalyst Synthesis}

2.2.1. Impregnation. Untreated (as synthesized) fishbone carbon nanofibres as well as CNFs that were surface oxidized with concentrated nitric acid or a mixture of concentrated nitric and sulphuric acid were used for the impregnation of an aqueous solution of $\mathrm{RhCl}_{3} \cdot 2 \mathrm{H}_{2} \mathrm{O}$. 
Ten grams of CNFs were boiled in $40 \mathrm{ml}$ of $\mathrm{HNO}_{3}$ or $80 \mathrm{ml}$ of $\mathrm{HNO}_{3} / \mathrm{H}_{2} \mathrm{SO}_{4}(1: 1)$ for $60 \mathrm{~min}\left(\mathrm{HNO}_{3}\right.$, Lamers \& Pleuger, 65\%, pure; $\mathrm{H}_{2} \mathrm{SO}_{4}$, Merck, 95-97\%, p.a.). Upon cooling and dilution with demineralized water, the suspensions were filtered over a Teflon membrane filter with a pore diameter of $0.2 \mu \mathrm{m}$, washed with water until the washings showed no significant acidity, and dried at $120^{\circ} \mathrm{C}$ for $16 \mathrm{~h}$.

The total pore volume of the differently treated fibres was determined by adding demineralized water to degassed CNFs with a syringe until the fibres had a sticky appearance. The values obtained were about $0.4 \mathrm{ml} / \mathrm{g}$. Next, degassed CNFs were impregnated in static vacuum with an aqueous solution of $\mathrm{RhCl}_{3} \cdot 2 \mathrm{H}_{2} \mathrm{O}$ with a concentration of about $0.3 \mathrm{~mol} / \mathrm{L}$ in order to get a rhodium metal loading of $1 \mathrm{wt} \%$. Degassing of the fibres was performed by evacuation at room temperature for several hours. The Rh-impregnated fibres were dried at room temperature for $36 \mathrm{~h}$ and, subsequently, dried at $120^{\circ} \mathrm{C}$ for $17 \mathrm{~h}$.

The Rh-impregnated fibres were subjected to several calcination-reduction procedures. The catalysts were either calcined and then reduced or directly reduced. Calcination took place at 150 or $250^{\circ} \mathrm{C}$ (stagnant air, $\left.5^{\circ} \mathrm{C} / \mathrm{min}, 1 \mathrm{~h}\right)$, while the subsequent reduction temperature was 140 or $250^{\circ} \mathrm{C}$ $\left(10 \% \mathrm{H}_{2} / \mathrm{Ar}, 5.6^{\circ} \mathrm{C} / \mathrm{min}, 20 \mathrm{~min}\right)$. The reduction temperature for the direct reduction was either 160 or $250^{\circ} \mathrm{C}$. The reductions at lower temperatures were monitored with a hot wire detector (HWD). The several calcination-reduction treatments along with the catalyst codes are shown in Table 1 for the $\mathrm{HNO}_{3} / \mathrm{H}_{2} \mathrm{SO}_{4}$-oxidized fibres. The untreated and the $\mathrm{HNO}_{3}$-oxidized fibres were not coded.

TABLE 1

\section{Catalyst Codes for $\mathrm{HNO}_{3} / \mathrm{H}_{2} \mathrm{SO}_{4}$-Oxidized Carbon Nanofibres}

\begin{tabular}{|c|c|}
\hline Code & Description \\
\hline $\mathrm{Rh} / \mathrm{CNF}(\mathrm{imp}, \mathrm{c} 150, \mathrm{r} 140)$ & $\begin{array}{l}\text { Impregnated, calcined at } 150^{\circ} \mathrm{C}, \\
\quad \text { reduced at } 140^{\circ} \mathrm{C}\end{array}$ \\
\hline $\mathrm{Rh} / \mathrm{CNF}$ (imp, c250, r140) & $\begin{array}{l}\text { Impregnated, calcined at } 250^{\circ} \mathrm{C}, \\
\quad \text { reduced at } 140^{\circ} \mathrm{C}\end{array}$ \\
\hline $\mathrm{Rh} / \mathrm{CNF}(\mathrm{imp}, \mathrm{r} 160)$ & Impregnated, reduced at $160^{\circ} \mathrm{C}$ \\
\hline $\mathrm{Rh} / \mathrm{CNF}(\mathrm{imp}, \mathrm{c} 150, \mathrm{r} 250)$ & $\begin{array}{l}\text { Impregnated, calcined at } 150^{\circ} \mathrm{C}, \\
\text { reduced at } 250^{\circ} \mathrm{C}\end{array}$ \\
\hline $\mathrm{Rh} / \mathrm{CNF}$ (imp, c250, r250) & $\begin{array}{l}\text { Impregnated, calcined at } 250^{\circ} \mathrm{C} \text {, } \\
\text { reduced at } 250^{\circ} \mathrm{C}\end{array}$ \\
\hline $\mathrm{Rh} / \mathrm{CNF}$ (imp, r250) & Impregnated, reduced at $250^{\circ} \mathrm{C}$ \\
\hline $\mathrm{Rh} / \mathrm{CNF}(\mathrm{IET})$ & Ion exchanged at $100^{\circ} \mathrm{C}$, not reduced \\
\hline $\mathrm{Rh} / \mathrm{CNF}(\mathrm{IET}, \mathrm{r} 200)$ & $\begin{array}{l}\text { Ion exchanged at } 100^{\circ} \mathrm{C} \text {, reduced } \\
\text { at } 200^{\circ} \mathrm{C}\end{array}$ \\
\hline $\mathrm{Rh} / \mathrm{CNF}\left(\mathrm{IET}, \mathrm{rNaBH}_{4}\right)$ & $\begin{array}{l}\text { Ion exchanged at } 100^{\circ} \mathrm{C} \text {, reduced } \\
\text { with } \mathrm{NaBH}_{4}\end{array}$ \\
\hline $\mathrm{Rh} / \mathrm{CNF}(\mathrm{IEN}, \mathrm{r} 200)$ & $\begin{array}{l}\text { Ion exchanged with } \mathrm{NH}_{3} \text {, reduced } \\
\text { at } 200^{\circ} \mathrm{C}\end{array}$ \\
\hline $\mathrm{Rh} / \mathrm{CNF}(\mathrm{IENT}, \mathrm{r} 200)$ & $\begin{array}{l}\text { Ion exchanged with } \mathrm{NH}_{3} \text { at } 100^{\circ} \mathrm{C} \text {, } \\
\text { reduced at } 200^{\circ} \mathrm{C}\end{array}$ \\
\hline
\end{tabular}

Note. All catalysts contain $1 \mathrm{wt} \% \mathrm{Rh}$.
2.2.2. Ion exchange. Only fibres that were surface oxidized with $\mathrm{HNO}_{3} / \mathrm{H}_{2} \mathrm{SO}_{4}$ (see above) were used for ion exchange. As ion exchange with $\mathrm{RhCl}_{3} \cdot 2 \mathrm{H}_{2} \mathrm{O}$ in water was not successful at room temperature, $1 \mathrm{~g}$ of fibres was refluxed in $30 \mathrm{ml}$ of a $3.3 \times 10^{-3} \mathrm{~mol} / \mathrm{L}$ solution of $\mathrm{RhCl}_{3} \cdot 2 \mathrm{H}_{2} \mathrm{O}$ in demineralized water for $48 \mathrm{~h}$ (maximum loading $1 \mathrm{wt} \%$ ). Next, the ion-exchanged fibres were filtered and dried at $120^{\circ} \mathrm{C}$ for $17 \mathrm{~h}$. Subsequently, the catalysts were reduced either with $\mathrm{H}_{2}\left(10 \% \mathrm{H}_{2} / \mathrm{Ar}, 5.6^{\circ} \mathrm{C} / \mathrm{min}\right.$, $200^{\circ} \mathrm{C}, 20 \mathrm{~min}$ ) or with $\mathrm{NaBH}_{4}$. Reduction with $\mathrm{NaBH}_{4}$ was carried out by dispersing $1 \mathrm{~g}$ of ion-exchanged catalyst in $10 \mathrm{ml}$ of ethanol (Merck, p.a.) and by adding $55 \mathrm{mg}$ of $\mathrm{NaBH}_{4}$ (Alfa, 99\%) in $10 \mathrm{ml}$ of ethanol. The evolution of gas indicated an immediate reaction. After being stirred for $30 \mathrm{~min}$ at room temperature, the reduced catalyst was filtered from the colourless solution, washed with ethanol, and dried under vacuum at room temperature for $17 \mathrm{~h}$.

The ion-exchange procedure was also carried out in a $4 \%$ ammonia solution at room temperature and at refluxing conditions for $48 \mathrm{~h}$. Again, the solution contained enough rhodium to obtain a $1 \mathrm{wt} \%$ catalyst. These catalysts were reduced at $200^{\circ} \mathrm{C}$ in $\mathrm{H}_{2}\left(10 \% \mathrm{H}_{2} / \mathrm{Ar}, 5.6^{\circ} \mathrm{C} / \mathrm{min}, 20 \mathrm{~min}\right)$.

Table 1 summarizes the several ion-exchange procedures together with the accompanying catalyst codes.

\subsection{Characterization}

Characterization of the catalysts was carried out by scanning electron microscopy (SEM), transmission electron microscopy (TEM), and X-ray absorption fine structure (XAFS) spectroscopy.

2.3.1. Electron microscopy. SEM images were obtained on a Philips XL30FEG microscope at an accelerating voltage of $20 \mathrm{kV}$. TEM samples were prepared by dispersing ground catalyst in ethanol using ultrasound and drying a drop on a copper grid covered by a holey carbon film. They were imaged in a Philips CM-200 FEG electron microscope operating at $200 \mathrm{kV}$ and in a Philips EM-420 electron microscope operated at an accelerating voltage of $120 \mathrm{kV}$. The CM-200 microscope was equipped with a field emission gun and an EDX facility for elemental analysis.

2.3.2. XAFS data collection. XAFS spectra at the Rh $K$-edge $(23,220 \mathrm{eV})$ were obtained at the HASYLAB (Hamburg, Germany) synchrotron beamline X1.1, which was equipped with a $\mathrm{Si}(311)$ double-crystal monochromator. The monochromator was detuned to $50 \%$ of the maximum intensity to minimize the presence of higher harmonics. All measurements were performed in the transmission mode using ionization chambers filled with an $\mathrm{Ar} / \mathrm{N}_{2}$ mixture to have an absorbance of 20 and $80 \%$ in the first and the second ionization chambers, respectively.

The powdered CNF samples (300 mg) were pressed into self-supporting wafers and mounted into an in situ EXAFS cell equipped with Be windows (19). Due to the low 
concentration of $\mathrm{Rh}(1 \mathrm{wt} \%)$ and the low absorption of carbon, the calculated edge step was about 0.2. The $\mathrm{Rh}_{2} \mathrm{O}_{3}$ reference compound (Aldrich, 99.8\%) was diluted with boron nitride (Alfa, 99.8\%) and pressed into a self-supporting wafer (calculated edge step 1). The rhodium reference foil (Aldrich, 99.9\%, 25- $\mu$ m thickness) was mounted on the sample holder with Kapton tape. All samples (except $\mathrm{Rh} / \mathrm{CNF}(\mathrm{IET})$ and $\mathrm{Rh} / \mathrm{CNF}\left(\mathrm{IET}, \mathrm{rNaBH}_{4}\right)$ ) were in situ reduced $\left(10 \% \mathrm{H}_{2} / \mathrm{He}, 5^{\circ} \mathrm{C} / \mathrm{min}, 1 \mathrm{~h}\right)$ and cooled to liquid nitrogen temperature prior to measurement. All gasses were purified before use.

It should be noted that with all catalysts, edge steps in the $\mathrm{X}$-ray absorption spectra were obtained that were equal to the theoretical edge step for $1 \mathrm{wt} \% \mathrm{Rh}$ on carbon. In other words, all catalysts indeed contain $1 \mathrm{wt} \% \mathrm{Rh}$.

\subsubsection{XAFS data processing. Extraction of the EXAFS} data from the measured absorption spectra was performed with the XDAP code developed by Vaarkamp et al. (20) Two scans were averaged and the pre-edge was subtracted using a modified Victoreen curve (21). The background was subtracted employing cubic spline routines with a continuously adjustable smooth parameter $(22,23)$. Normalization was performed by dividing the data by the height of the absorption edge at $50 \mathrm{eV}$, leading to normalised EXAFS data.

\subsubsection{EXAFS phase shifts and backscattering amplitudes.} Data for phase shifts and backscattering amplitudes were obtained from the reference compounds: $\mathrm{Rh}$ foil for $\mathrm{Rh}-\mathrm{Rh}$ and $\mathrm{Rh}_{2} \mathrm{O}_{3}$ for $\mathrm{Rh}-\mathrm{O}$ contributions (23). It is well-known that differences in backscattering amplitude and phase shift of neighbours and next nearest neighbours in the periodic system are too small to make a distinction between the two scatterers (24). Therefore, the contribution of $\mathrm{Rh}-\mathrm{C}$ was fitted with the $\mathrm{Rh}-\mathrm{O}$ reference. Table 2 gives the crystallographic data and the forward and inverse Fourier transform ranges used to create the EXAFS references. Both the reference spectra and the samples were measured at liquid nitrogen temperature. This means that no temperature effect has to be included in the difference in Debye-Waller factor $\left(\Delta \sigma^{2}\right)$ between sample and reference as obtained in the EXAFS data analysis.

\section{TABLE 2}

Crystallographic Data and the Forward and Inverse Fourier Transform Ranges Used to Produce the EXAFS References

\begin{tabular}{llrrrrrr}
\hline $\begin{array}{c}\text { Atom } \\
\text { pair }\end{array}$ & $\begin{array}{c}\text { Ref. } \\
\text { compd. }\end{array}$ & Ref. & $N^{\text {ref }}$ & $R^{\text {ref }}(\AA)$ & $k^{n}$ & $\begin{array}{c}\text { Forward FT } \\
(\Delta K)\left(\AA^{-1}\right)\end{array}$ & $\begin{array}{c}\text { Inverse FT } \\
(\Delta R)(\AA)\end{array}$ \\
\hline $\mathrm{Rh}-\mathrm{Rh}$ & $\mathrm{Rh}_{\text {foil }}$ & 25 & 12 & 2.69 & $k^{3}$ & $2.7-22.7$ & $1.4-3.1$ \\
$\mathrm{Rh}-\mathrm{O}$ & $\mathrm{Rh}_{2} \mathrm{O}_{3}{ }^{a}$ & 26 & 6 & 2.05 & $k^{1}$ & $3.7-16.3$ & $0.0-2.3$
\end{tabular}

${ }^{a}$ It was established with XRD that the $\mathrm{Rh}_{2} \mathrm{O}_{3}$ was in the hexagonal form.
2.3.5. R-space fitting, difference file technique, and weight factor $k^{n}$. The EXAFS data-analysis program XDAP allows multiple-shell fitting in $R$-space by minimizing the residuals between both the magnitude and the imaginary part of the Fourier transforms of the data and the fit. $R$-space fitting has important advantages compared to the usually applied fitting in $k$-space and is extensively discussed in a recent paper by Koningsberger et al. (23).

The difference file technique was applied together with phase-corrected Fourier transforms to resolve the different contributions in the EXAFS data (23). The difference file technique allows one to optimize each individual contribution with respect to the other contributions present in the EXAFS spectrum. If the experimental spectrum is composed of different contributions, then

$$
\text { Exp.Data }=\sum_{i=1}^{N}(\text { Fit })_{i},
$$

where (Fit) ${ }_{i}$ represents the fitted contribution of coordination shell $i$. For each individual contribution the following equation should then be valid:

$$
(\text { Fit })_{j}=\text { Exp.Data }-\sum_{i=1 \text { and } i \neq j}^{N}(\text { Fit })_{i} .
$$

The right-hand side of this equation is further denoted as the difference file of shell $j$. A good fit is only obtained if the total fit and each individual contributing coordination shell describe correctly the experimental EXAFS and the difference file, respectively. In this way not only the total EXAFS fit but also the individual fits of all separate contributions can be determined reliably.

Both high-Z (e.g., metal-metal) and low-Z (e.g., metaloxygen) contributions are present in the EXAFS data collected on small metal particles dispersed on high-surfacearea supports. The low- $Z$ contributions may arise from the support. A $k^{3}$ weighting emphasizes the high-Z contributions to the spectrum, since high- $Z$ elements have more scattering power at high values of $k$ than do low-Z elements. However, the use of a $k^{3}$-weighted EXAFS spectrum or Fourier transform makes the analysis much less sensitive to the presence of low- $Z$ contributions in the EXAFS data. In this study, the EXAFS fits have been checked by applying $k^{1}, k^{2}$, and $k^{3}$ weightings in order to be certain that the results are the same for all weightings.

2.3.6. Number of independent data points, variance, and statistical significance. The number of independent data points $\left(N_{\text {indp }}\right)$ was determined as outlined in $(27,28)$ :

$$
N_{\text {indp }}=(2 \Delta k \Delta R / \pi)+2 .
$$

The variances of the magnitude and imaginary part of the Fourier transforms of fit and data were calculated according 
to the equation

$$
\text { Variance }=\frac{\int\left[\mathrm{FT}_{\text {model }}^{n}(R)-\mathrm{FT}_{\text {exp }}^{n}(R)\right]^{2} d R}{\int\left[\mathrm{FT}_{\mathrm{exp}}^{n}(R)\right]^{2} d R} \times 100,
$$

with $\mathrm{FT}^{n}=\mathrm{FT}\left[k^{n} \chi(k)\right]$. In this study the statistical significance of a contribution has been checked by a comparison of the amplitude of (Fit) ${ }_{j}$ with the noise level present in the difference file (the noise in the difference file is essentially the same as the noise in the experimental data).

2.3.7. Estimation of particle size. The average particle size of the various catalysts was estimated from the $\mathrm{Rh}-$ $\mathrm{Rh}$ coordination numbers obtained with EXAFS by using a computer program (29). The program "cuts" spherical or semispherical particles with different diameters from a $\mathrm{Rh}$ fcc crystal and calculates the average coordination number and the number of atoms in the particle.

\subsection{Catalytic Test Experiments}

The catalytic activity of the $\mathrm{Rh} / \mathrm{CNF}$ catalysts in the hydrogenation of cyclohexene was tested in a semibatch slurry reactor, operated at a constant pressure of 1200 mbar of $\mathrm{H}_{2}$. The thermostated, double-walled reaction vessel was equipped with vertical baffles and a gas-tight stirrer with a hollow shaft and blades for gas recirculation. The stirrer was operated at $2000 \mathrm{rpm}$. During reaction, the hydrogen consumption was automatically monitored by a mass flow meter. It was assured that under the conditions used, the rate of dissolution of $\mathrm{H}_{2}$ in the solvent was higher than the maximum measurable rate of $\mathrm{H}_{2}$ uptake.

In a typical experiment, the reaction vessel was filled with $50 \mathrm{mg}$ of powdered catalyst and $100 \mathrm{ml}$ of ethanol (Merck p.a.). Next, the reactor was thermostated at $25^{\circ} \mathrm{C}$, evacuated, filled with $\mathrm{H}_{2}$, and pressurized. After being stirred for $1 \mathrm{~h}$ under $\mathrm{H}_{2}$ in order to reduce the catalyst, the reaction was started by injection of $1 \mathrm{ml}$ of cyclohexene (Acros, $99 \%$ ) with a syringe.

The presence or absence of internal diffusion limitations was checked by calculation of the internal effectiveness factor $\eta$, using the expression (30)

$$
\eta=\tanh (\varphi) / \varphi
$$

with

$$
\varphi=1 / a_{v}^{\prime} \sqrt{ }\left(k_{v, p} / D_{e A}\right),
$$

where $\varphi$ is the Thiele modulus, $k_{v, p}$ is the reaction rate constant per unit catalyst volume, and $D_{e A}$ is the effective diffusion constant for reactant $A . a_{v}^{\prime}$ is the ratio between the external surface area and the volume of the catalyst particle. Values of $\eta$ close to 1 indicate that internal diffusion limitations are absent.

For spherical particles $a_{v}^{\prime}$ is given by

$$
a_{v}^{\prime}=6 / d_{p}
$$

where $d_{p}$ is the particle diameter. $D_{e A}$ is given by

$$
D_{e A}=\left(\varepsilon_{p} D_{A}\right) / \tau_{p}
$$

where $D_{A}$ is the diffusion coefficient of reactant $A, \varepsilon_{p}$ is the void fraction of the particle, and $\tau_{p}$ is the tortuosity of the particle. The reaction rate constant $k_{v, p}$ can be obtained from

$$
C_{A}=C_{A 0} e^{-k_{1} t}
$$

assuming a first-order reaction. $C_{A}$ is the concentration of reactant at time $t, C_{A 0}$ is the initial concentration, and $k_{1}$ is the reaction rate constant per unit reactor volume. $k_{1}$ can easily be converted to $k_{v, p}$ by multiplying it with the ratio of reactor volume and catalyst volume.

Because the $k_{v, p}$ thus obtained is an observed reaction rate constant, which can be influenced by diffusion, the calculation should be made cyclic: $\eta$ should be used to calculate an intrinsic reaction rate constant by dividing $k_{v, p}$ with $\eta$ and the calculation should be repeated until no more changes are observed. In this way, a good approximation of the intrinsic reaction rate constant can be obtained.

\section{RESULTS}

\subsection{Scanning Electron Microscopy}

Figure 1 displays two SEM images of powdered fishbone carbon nanofibres treated with $\mathrm{HNO}_{3} / \mathrm{H}_{2} \mathrm{SO}_{4}$. Figure $1 \mathrm{~A}$ shows that the bodies of entangled fibres in this sample exhibit a broad particle size distribution. However, no nanofibre particles larger than about $50 \mu \mathrm{m}$ are observed. Most CNF particles have a dimension between 5 and $20 \mu \mathrm{m}$. At larger magnification (Fig. 1B) the individual fibres become visible. The fibres are entangled and form an open, macroporous structure. The pore structure of the fibres consists only of mesopores, which are located between individual fibres in a cluster (31). The fibres themselves are not porous and, consequently, metal particles will only be located at the outer surface of the fibres.

\subsection{Transmission Electron Microscopy}

The size and distribution of the rhodium particles on untreated, $\mathrm{HNO}_{3}$-oxidized and $\mathrm{HNO}_{3} / \mathrm{H}_{2} \mathrm{SO}_{4}$-oxidized fibres were examined with TEM (see Fig. 2). Within the untreated CNFs rhodium particles are found only very locally. No rhodium particles are observed on the carbon nanofibres (see Fig. 2A). However, many rhodium particles have been deposited on the holey carbon film (see Fig. 2B). Most of the deposited rhodium particles are smaller than $10 \mathrm{~nm}$, but larger particles up to $80 \mathrm{~nm}$ have been found as well. Detected rhodium is always associated with the presence of $\mathrm{Al}_{2} \mathrm{O}_{3}$ in these fibres (originating from the $\mathrm{Ni} / \mathrm{Al}_{2} \mathrm{O}_{3}$ growth catalyst).

With the $\mathrm{HNO}_{3}$-oxidized carbon nanofibres most fibres are also bare (see Fig. 2C). Only occasionally are large $\mathrm{Rh}$ 

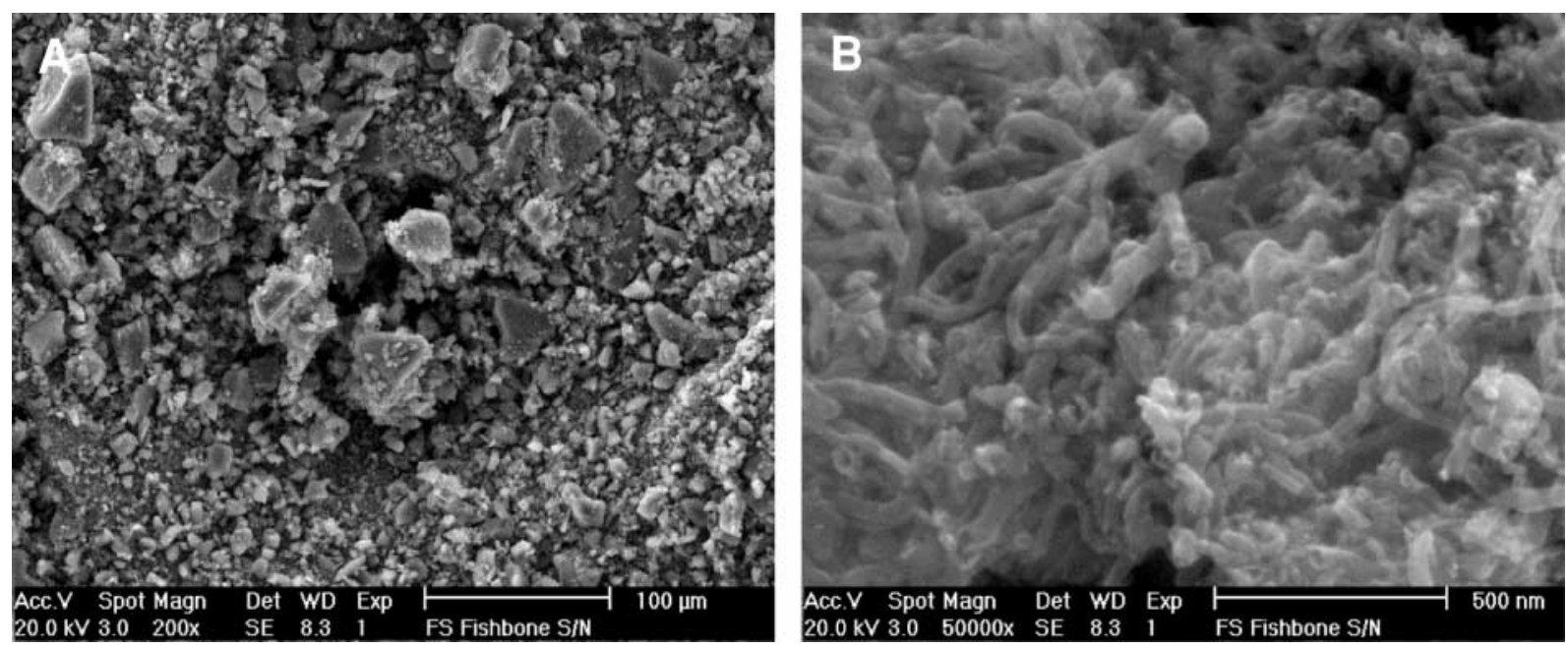

FIG. 1. SEM images of $\mathrm{HNO}_{3} / \mathrm{H}_{2} \mathrm{SO}_{4}$-oxidized fishbone carbon nanofibres at different magnifications. (A) The skeins of fibres; (B) the individual CNFs.

particles detected on the CNFs. EDX analysis revealed that $\mathrm{Rh}$ was only present within clusters of fibres. An example is shown in Fig. 2D. These rhodium particles are probably large as well.

In spite of an extended study, no rhodium particles could be imaged at all on the fibres that had been treated with $\mathrm{HNO}_{3} / \mathrm{H}_{2} \mathrm{SO}_{4}$. The diffraction contrast of the fibres themselves hinders the imaging of very small rhodium particles. However, when an EDX analysis was performed on a single fibre (see Figs. 2E and 2F) some rhodium could be detected. The $\mathrm{Cu}$ observed originates from the copper grid, the $\mathrm{Al}$ comes from some $\mathrm{Al}_{2} \mathrm{O}_{3}$ that remained in the sample after the oxidation treatment, and the $\mathrm{Si}$ is probably introduced during the oxidation treatment (in a glass round-bottomed flask).

\subsection{Reduction of the Catalysts}

The impregnated catalysts were first reduced at the lowest reduction temperature possible $\left(140^{\circ} \mathrm{C}\right.$ for the reduction of $\mathrm{Rh}_{2} \mathrm{O}_{3}$ and $160^{\circ} \mathrm{C}$ for the reduction of $\mathrm{RhCl}_{3} \cdot 2 \mathrm{H}_{2} \mathrm{O}$ ). These temperature levels and the temperatures for the calcination of $\mathrm{RhCl}_{3} \cdot 2 \mathrm{H}_{2} \mathrm{O}$ were determined using in situ temperature-programmed XRD on pure $\mathrm{Rh}_{2} \mathrm{O}_{3}$ and $\mathrm{RhCl}_{3} \cdot 2 \mathrm{H}_{2} \mathrm{O}$.

Figure 3 shows the reduction profile of $\mathrm{Rh} / \mathrm{CNF}$ (imp, $\mathrm{c} 250, \mathrm{r} 140)$. The left part of the figure exhibits the reduction profile during the temperature ramp up to $140^{\circ} \mathrm{C}$. Because the plotted temperature is the temperature within the reactor and the temperature controller uses the temperature of the furnace, the temperature of the catalyst bed is lower than $140^{\circ} \mathrm{C}$ after the ramp. After a period of stabilization of the temperature (during which the $\mathrm{H}_{2}$ consumption is not monitored), the catalyst bed reaches a temperature of $140^{\circ} \mathrm{C}$ and the reduction is continued isothermally for
20 min (right-hand part of the figure). The figure shows that the reduction of $\mathrm{Rh} / \mathrm{CNF}(\mathrm{imp}, \mathrm{c} 250, \mathrm{r} 140$ ) had just completed at the termination of the program. The same results were obtained for $\mathrm{Rh} / \mathrm{CNF}$ (imp, c150, r150) and $\mathrm{Rh} / \mathrm{CNF}(\mathrm{imp}, \mathrm{r} 160)$. The reductions at higher temperatures were not monitored.

\subsection{XAFS Spectroscopy}

3.4.1. XAFS analysis. Figure 4 shows the experimental EXAFS data of Rh/CNF(imp, c150, r140) (Fig. 4A) and $\mathrm{Rh} / \mathrm{CNF}$ (imp, c150, r250) (Fig. 4C). The data quality is excellent. The signal-to-noise ratio at $k=4 \AA^{-1}$ amounts to approximately 120 for $\mathrm{Rh} / \mathrm{CNF}(\mathrm{imp}, \mathrm{c} 150, \mathrm{r} 140)$ and 90 for $\mathrm{Rh} / \mathrm{CNF}(\mathrm{imp}, \mathrm{c} 150, \mathrm{r} 250)$. It can clearly be seen that the EXAFS intensity of Rh/CNF(imp, c150, r250) at larger values of $k\left(k>10 \AA^{-1}\right)$ is higher than for $\mathrm{Rh} / \mathrm{CNF}$ (imp, $\mathrm{c} 150, \mathrm{r} 140)$, indicating the presence of larger rhodium particles. The corresponding $k^{1}$-Fourier transforms of both catalysts (Figs. 4B and 4D) confirm this observation. The peak at $2.5 \AA$ originating from the $\mathrm{Rh}-\mathrm{Rh}$ contribution has a higher intensity with $\mathrm{Rh} / \mathrm{CNF}(\mathrm{imp}, \mathrm{c} 150, \mathrm{r} 250)$ than with $\mathrm{Rh} / \mathrm{CNF}$ (imp, c150, r140).

The Fourier transform (FT) of the experimental EXAFS data of Rh/CNF(imp, c150, r140) together with the FT of the total fit is shown in Fig. 5A. The fit quality is excellent for the used fit range ( $\Delta R=1-2.8 \AA$ ). In $\mathrm{Rh} / \mathrm{CNF}$ (imp, c150, r140) $\mathrm{Rh}-\mathrm{Rh}$ and $\mathrm{Rh}-\mathrm{C}$ contributions could be established. The phase-corrected Fourier transforms of the fits of the two individual contributions together with their corresponding difference files are shown in Fig. 5B and 5C for the Rh$\mathrm{Rh}$ and $\mathrm{Rh}-\mathrm{C}$ contributions, respectively. The fit quality of each individual contribution is very good. The statistical significance of the fits is demonstrated in Fig. 5D. The calculated $k^{0}$-weighted $\mathrm{Rh}-\mathrm{Rh}$ and $\mathrm{Rh}-\mathrm{C}$ EXAFS spectra 

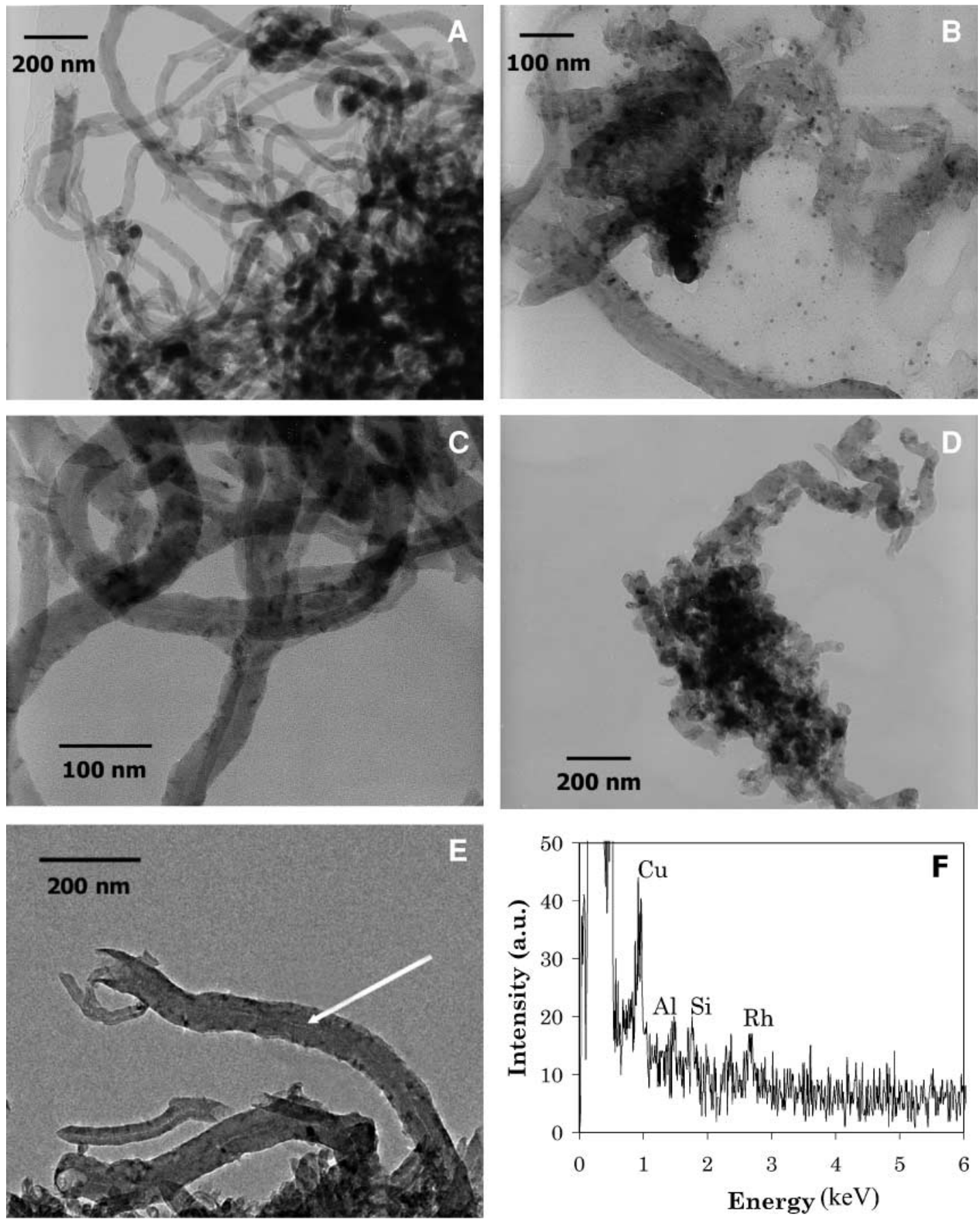

FIG. 2. (A, B) TEM images of rhodium impregnated untreated CNFs (calc. $150^{\circ} \mathrm{C}$, red. $140^{\circ} \mathrm{C}$ ). (C, D) TEM images of rhodium impregnated $\mathrm{HNO}_{3}$-oxidized CNFs (calc. $150^{\circ} \mathrm{C}$, red. $140^{\circ} \mathrm{C}$ ). (E) TEM image of Rh/CNF(imp, c150, r140). (F) EDX spot analysis of area indicated with a white arrow in $(\mathrm{E})$.

that are shown in the figure can be compared with the dotted lines approximately indicating the maximum (peak to peak) noise levels. It is shown that the $\mathrm{Rh}-\mathrm{C}$ contribution has a higher intensity than the noise level up to high $k$ values, demonstrating that reliable fit results for the weaker $\mathrm{Rh}-\mathrm{C}$ contribution have been obtained as well.
Table 3 presents the fit parameters of the EXAFS spectra resulting from the multiple-shell fits in $R$-space and the variances of the imaginary and absolute part of the fits for all catalysts. All variances obtained are well below 1\%, indicating that excellent fit results for all catalysts have been acquired (23). Furthermore, the calculated number of 


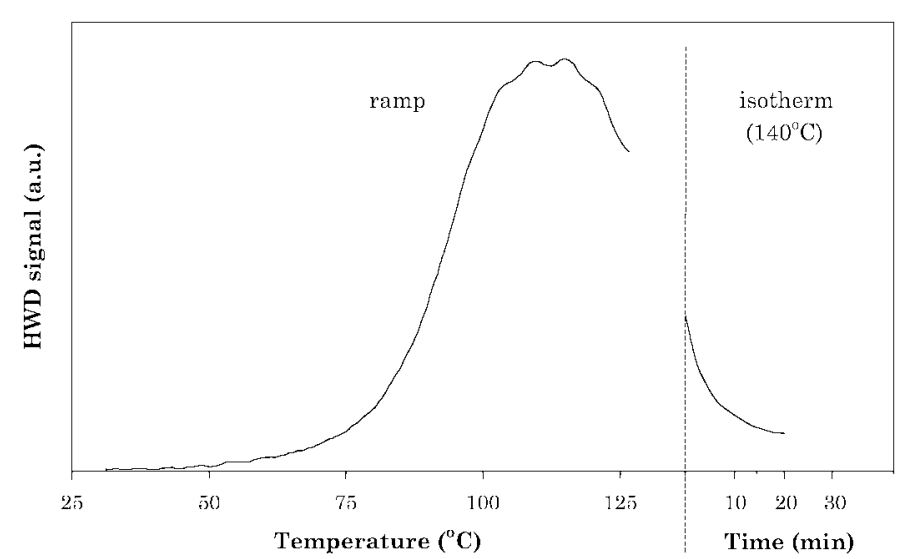

FIG. 3. Hydrogen consumption profile during reduction of $\mathrm{Rh} / \mathrm{CNF}$ (imp, c250, r140).
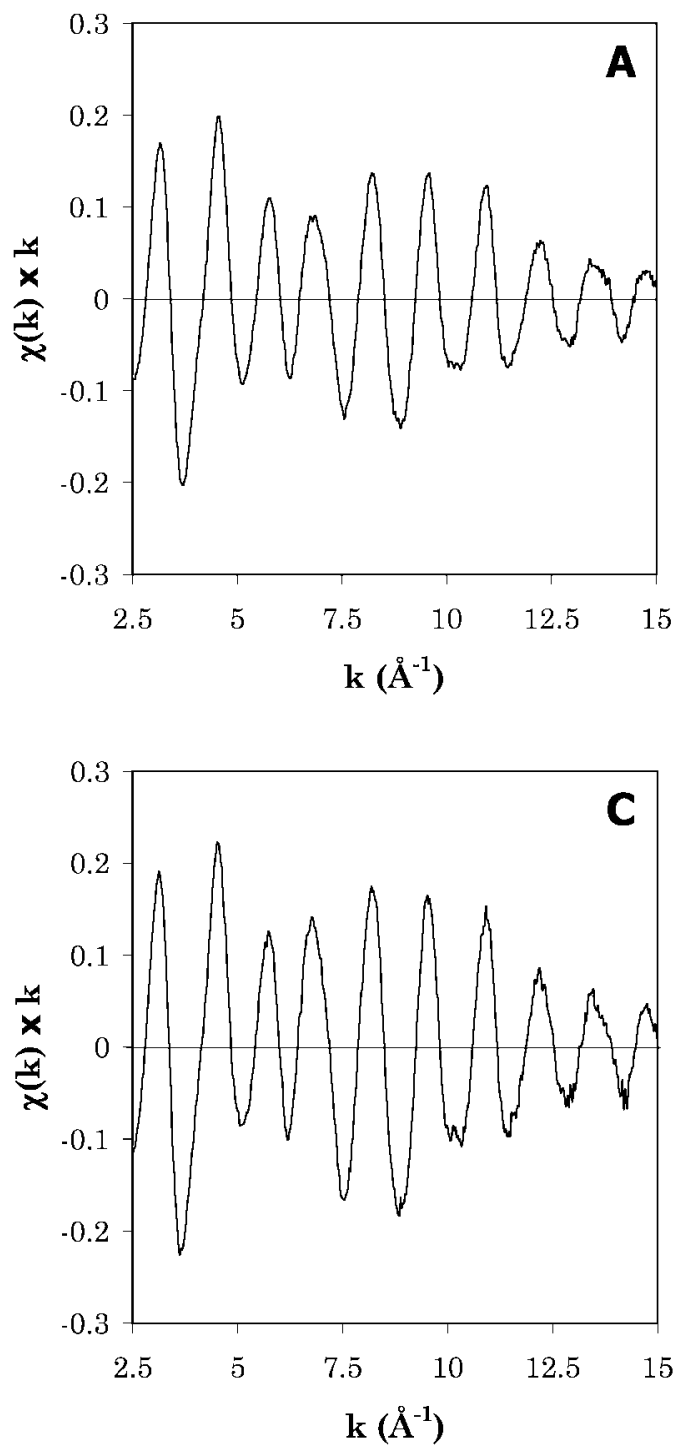

independent data points ( $N_{\text {indp }}$, see Eq. [3]) is 14, showing that a fit with three shells is possible $\left(N_{\text {indp }}=12\right)$. With $\mathrm{Rh} / \mathrm{CNF}(\mathrm{imp}, \mathrm{c} 150, \mathrm{r} 140)$ the Rh-Rh coordination number amounts to 5.8. Furthermore, 2.2 carbon atoms are distinguished at a distance of $2.7 \AA$. Upon reduction at $250^{\circ} \mathrm{C}$ the $\mathrm{Rh}-\mathrm{Rh}$ coordination number increases to 7.7 [Rh/CNF(imp, c150, r250)]. An increase can also be observed with the catalysts that were calcined at $250^{\circ} \mathrm{C}$ and those that were directly reduced. Furthermore, calcination at either 150 or $250^{\circ} \mathrm{C}$ does not influence the coordination number of the rhodium atoms obtained. Direct reduction results in a larger coordination number at low reduction temperatures than does calcination-reduction. At a reduction temperature of $250^{\circ} \mathrm{C}$ this effect almost disappears.
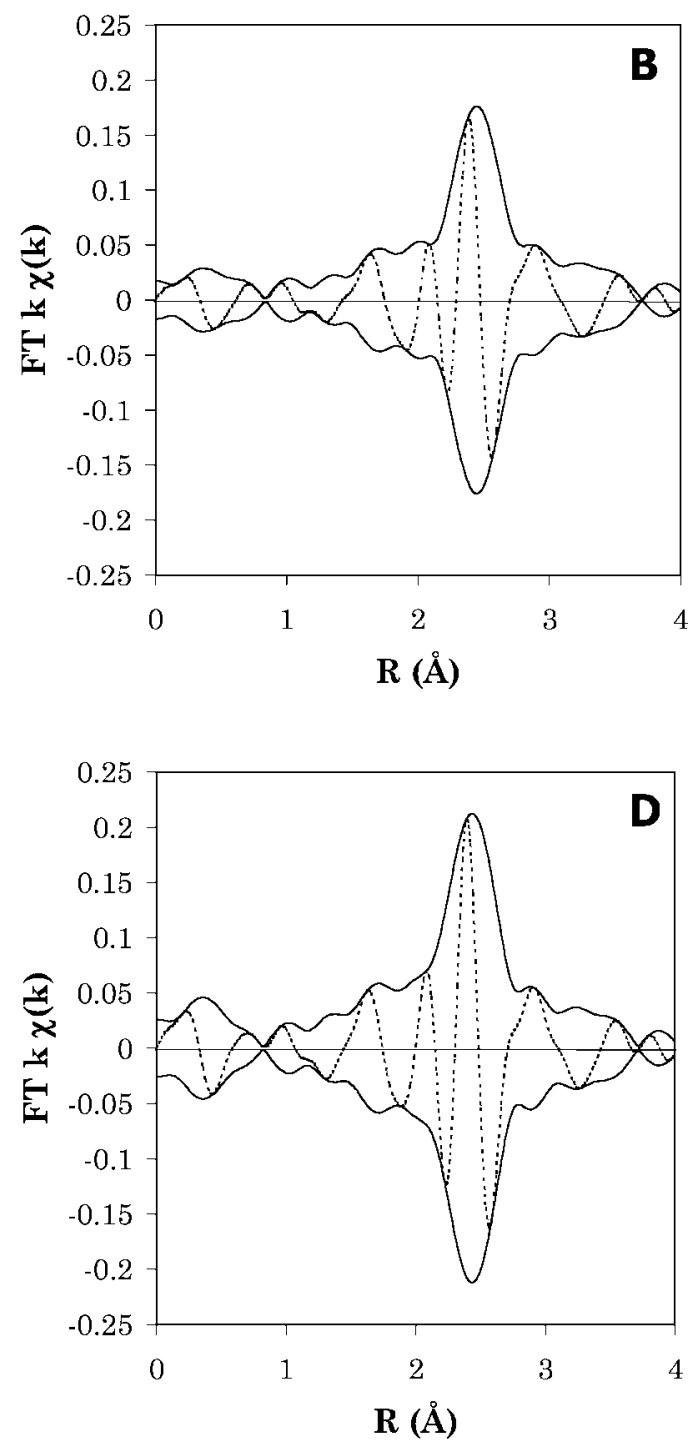

FIG. 4. (A) Experimental $k^{1}$-weighted EXAFS spectrum of Rh/CNF(imp, c150, r140). (B) Corresponding uncorrected Fourier transform ( $k^{1}$ weighted, $\Delta k=3.9-14 \AA^{-1}$ ). (C) Experimental $k^{1}$-weighted EXAFS spectrum of Rh/CNF(imp, c150, r250). (D) Corresponding uncorrected Fourier transform ( $k^{1}$ weighted, $\left.\Delta k=3.9-14 \AA^{-1}\right)$. 

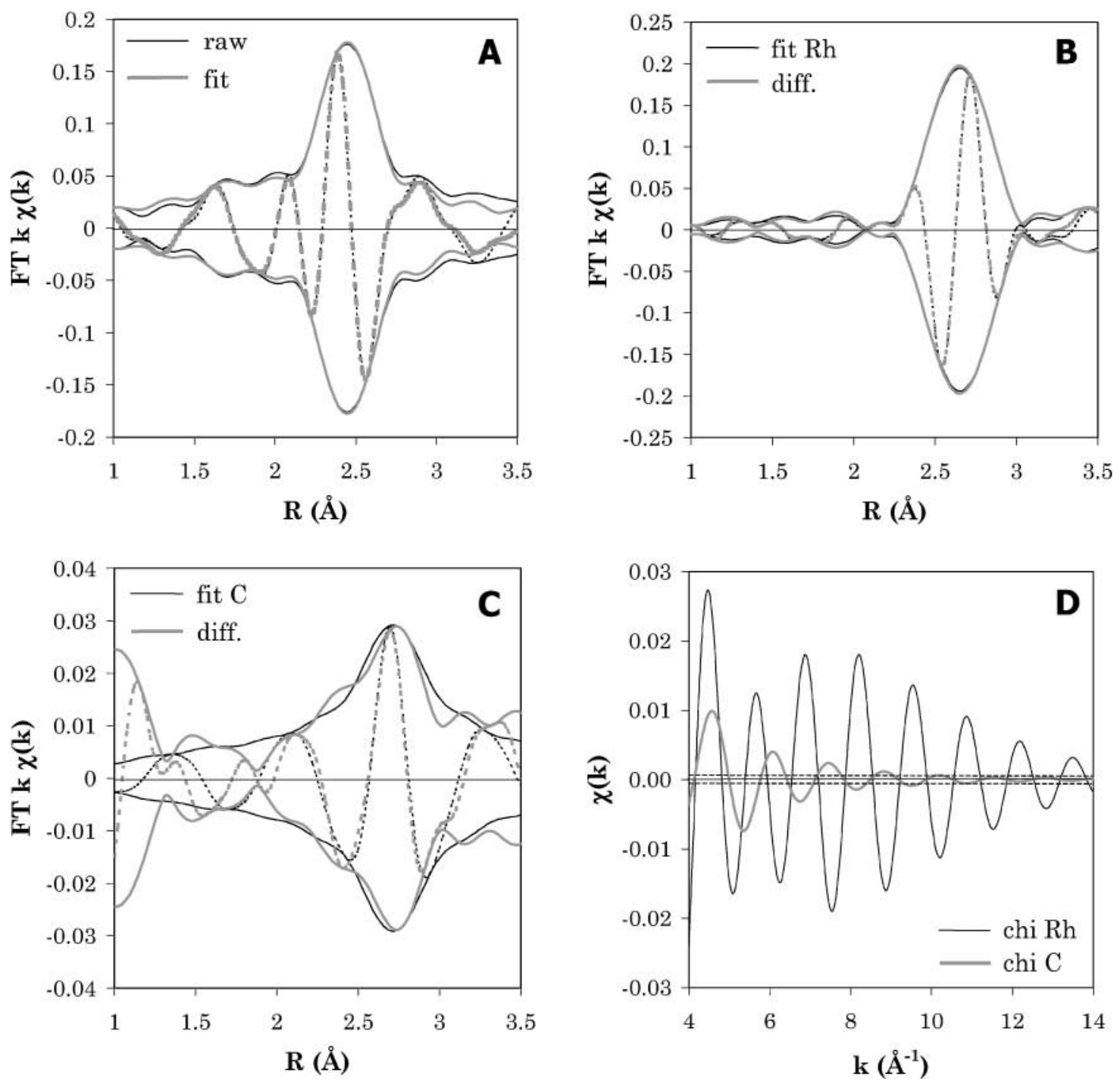

FIG. 5. Fit results of $\mathrm{Rh} / \mathrm{CNF}(\mathrm{imp}, \mathrm{c} 150, \mathrm{r} 140)\left(k^{1}\right.$ weighted, $\left.\Delta k=3.9-14 \AA^{-1}, \Delta R=1-2.8 \AA\right)$. (A) Fourier transform of experimental EXAFS data and total fit (uncorrected). (B) Rhodium-rhodium fit and corresponding difference file (Rh-Rh phase corrected). (C) Rhodium-carbon fit and corresponding difference file ( $\mathrm{Rh}-\mathrm{C}$ phase corrected). (D) Calculated $k^{0}$-weighted EXAFS spectrum of Rh-Rh and Rh-C fit. The two dotted lines indicate the noise level of the spectra.

With all impregnated catalysts a $\mathrm{Rh}-\mathrm{C}$ contribution can be distinguished.

Figures 6A, 6C, and 6E display the experimental EXAFS data of Rh/CNF(IET), Rh/CNF(IET, r200), and $\mathrm{Rh} / \mathrm{CNF}\left(\mathrm{IET}, \mathrm{rNaBH}_{4}\right.$ ), respectively. The signal-to-noise ratio at $k=4 \AA^{-1}$ of these spectra ranges from 50 to 70 . The EXAFS intensity of $\mathrm{Rh} / \mathrm{CNF}$ (IET) (Fig. 6A) is low at large $k$ values $\left(k>10 \AA^{-1}\right)$, indicating that high-Z scatterers are absent in this spectrum. Upon reduction with $\mathrm{H}_{2}$ (Fig. 6C) the spectrum totally changes. The high EXAFS intensity at large $k$ values $\left(k>10 \AA^{-1}\right)$ shows that a significant $\mathrm{Rh}-\mathrm{Rh}$ contribution is present. The spectrum of the catalyst that was reduced with $\mathrm{NaBH}_{4}$ (Fig. 6E) displays characteristics intermediate to that of the other catalysts. The $k^{2}$-Fourier transforms of the experimental EXAFS data are shown in
Fig. 6B, 6D, and 6F. Before reduction (Fig. 6B) mainly contributions at $1.6 \AA$ arising from low-Z scatterers are present. Upon reduction with $\mathrm{H}_{2}$ (Fig. 6D) an intense peak at $2.4 \AA$ points to the formation of rhodium particles. After reduction with $\mathrm{NaBH}_{4}$ (Fig. 6F) only a small Rh-Rh contribution at the same distance can be distinguished.

Figure 7 shows the fit results of $\mathrm{Rh} / \mathrm{CNF}\left(\mathrm{IET}, \mathrm{rNaBH}_{4}\right)$. Again, good results are obtained for the total fit and separate $\mathrm{Rh}-\mathrm{Rh}, \mathrm{Rh}-\mathrm{O}$, and $\mathrm{Rh}-\mathrm{C}$ contributions. At a distance of $2.68 \AA$ an average number of $3.8 \mathrm{Rh}$ neighbours is present (see Table 3 ). The coordination number of oxygen neighbours amounts to 4.7 at $2.05 \AA$. Finally, 1.5 carbon atoms are visible at a distance of $2.29 \AA$. Before reduction $[\mathrm{Rh} / \mathrm{CNF}(\mathrm{IET})]$ no $\mathrm{Rh}-\mathrm{Rh}$ can be fitted in the FT of the experimental EXAFS data. Four oxygen atoms are visible 
TABLE 3

Fit Parameters of EXAFS Spectra and Variances of Fits (see Eq. [4]) ${ }^{a}$

\begin{tabular}{|c|c|c|c|c|c|c|c|}
\hline \multirow[b]{2}{*}{ Catalyst } & \multirow[b]{2}{*}{ Atom } & \multirow{2}{*}{$\begin{array}{c}N \\
( \pm 5 \%)^{b}\end{array}$} & \multirow{2}{*}{$\begin{array}{c}R \\
(\AA))( \pm 1 \%)\end{array}$} & \multirow{2}{*}{$\begin{array}{c}\Delta \sigma^{2} \\
\left(\AA^{2}\right)( \pm 5 \%)\end{array}$} & \multirow{2}{*}{$\begin{array}{c}\Delta E_{0} \\
(\mathrm{eV})( \pm 10 \%)\end{array}$} & \multicolumn{2}{|c|}{$\operatorname{Variance}^{c}(\%)$} \\
\hline & & & & & & Im & Abs \\
\hline \multirow[t]{2}{*}{$\mathrm{Rh} / \mathrm{CNF}(\mathrm{imp}, \mathrm{c} 150, \mathrm{r} 140)$} & $\mathrm{Rh}$ & 5.8 & 2.68 & 0.002 & 5.5 & 0.37 & 0.21 \\
\hline & $\mathrm{C}$ & 2.2 & 2.70 & 0.000 & -3.6 & & \\
\hline \multirow[t]{2}{*}{$\mathrm{Rh} / \mathrm{CNF}(\mathrm{imp}, \mathrm{c} 250, \mathrm{r} 140)$} & $\mathrm{Rh}$ & 5.9 & 2.68 & 0.002 & 7.0 & 0.62 & 0.32 \\
\hline & $\mathrm{C}$ & 2.0 & 2.70 & 0.000 & -3.2 & & \\
\hline \multirow[t]{2}{*}{ Rh/CNF(imp, r160) } & $\mathrm{Rh}$ & 6.7 & 2.68 & 0.002 & 7.2 & 0.23 & 0.13 \\
\hline & $\mathrm{C}$ & 1.8 & 2.70 & 0.000 & -3.4 & & \\
\hline \multirow[t]{2}{*}{$\mathrm{Rh} / \mathrm{CNF}(\mathrm{imp}, \mathrm{c} 150, \mathrm{r} 250)$} & $\mathrm{Rh}$ & 7.7 & 2.68 & 0.002 & 7.2 & 0.18 & 0.10 \\
\hline & $\mathrm{C}$ & 2.3 & 2.70 & 0.000 & -7.3 & & \\
\hline \multirow[t]{2}{*}{$\mathrm{Rh} / \mathrm{CNF}(\mathrm{imp}, \mathrm{c} 250, \mathrm{r} 250)$} & $\mathrm{Rh}$ & 7.5 & 2.67 & 0.003 & 7.2 & 0.35 & 0.21 \\
\hline & $\mathrm{C}$ & 2.5 & 2.70 & 0.000 & -6.9 & & \\
\hline \multirow[t]{2}{*}{ Rh/CNF(imp, r250) } & $\mathrm{Rh}$ & 7.8 & 2.68 & 0.002 & 7.5 & 0.26 & 0.15 \\
\hline & $\mathrm{C}$ & 2.5 & 2.70 & 0.000 & -7.1 & & \\
\hline \multirow[t]{3}{*}{$\mathrm{Rh} / \mathrm{CNF}(\mathrm{IET})^{d}$} & $\mathrm{O}$ & 4.0 & 2.05 & 0.001 & -6.4 & 0.19 & 0.05 \\
\hline & $\mathrm{Cl}$ & 2.0 & 2.27 & 0.004 & 8.0 & & \\
\hline & $\mathrm{C}$ & 2.7 & 2.86 & 0.001 & -4.9 & & \\
\hline \multirow[t]{2}{*}{ Rh/CNF(IET, r200) } & $\mathrm{Rh}$ & 5.9 & 2.68 & 0.004 & 9.4 & 0.19 & 0.11 \\
\hline & $\mathrm{C}$ & 2.2 & 2.70 & 0.000 & -1.8 & & \\
\hline \multirow{3}{*}{$\mathrm{Rh} / \mathrm{CNF}\left(\mathrm{IET}, \mathrm{rNaBH}_{4}\right)^{d}$} & $\mathrm{Rh}$ & 3.8 & 2.68 & 0.010 & 7.8 & 0.49 & 0.20 \\
\hline & $\mathrm{O}$ & 4.7 & 2.05 & 0.001 & -2.1 & & \\
\hline & $\mathrm{C}$ & 1.5 & 2.29 & 0.008 & -5.6 & & \\
\hline Rh/CNF(IEN, r200) & $\mathrm{Rh}$ & 8.9 & 2.69 & 0.001 & 0.3 & 0.19 & 0.15 \\
\hline Rh/CNF(IENT, r200) & $\mathrm{Rh}$ & 8.7 & 2.69 & 0.001 & -0.8 & 0.23 & 0.17 \\
\hline
\end{tabular}

${ }^{a} \Delta k=3.9-14 \AA^{-1} ; \Delta R=1-2.8 \AA ; k^{1}$ weighted.

${ }^{b}$ For Rh-Rh. For low-Z scatterers the accuracy is estimated at $\pm 10-20 \%$.

${ }^{c}$ Variance of total fit.

${ }^{d} k^{2}$ fitted.

at $2.05 \AA$, two chlorine atoms reside at $2.27 \AA$, and 2.7 carbon atoms are distinguishable at $2.86 \AA$. After reduction with $\mathrm{H}_{2}[\mathrm{Rh} / \mathrm{CNF}(\mathrm{IET}, \mathrm{r} 200)]$ the coordination number of $\mathrm{Rh}$ amounts to 5.9 , and 2.2 carbon atoms are present at $2.70 \AA$.

Figure 8 shows the $\mathrm{Rh}-\mathrm{C}$ fits and the corresponding difference files of $\mathrm{Rh} / \mathrm{CNF}(\mathrm{imp}, \mathrm{c} 150, \mathrm{r} 140)$ and $\mathrm{Rh} / \mathrm{CNF}$ (IET, $\mathrm{rNaBH}_{4}$ ). After reduction with $\mathrm{H}_{2}$ a rhodium-carbon contribution is present at $2.70 \AA$, while after the use of $\mathrm{NaBH}_{4}$ as reductant a $\mathrm{Rh}-\mathrm{C}$ interaction is present at a much shorter distance, $2.29 \AA$ A.

The ion-exchanged catalysts that were prepared in the presence of $\mathrm{NH}_{3}$ and reduced at $200^{\circ} \mathrm{C}$ show the largest $\mathrm{Rh}-\mathrm{Rh}$ coordination number (see Table 3). Synthesis at room temperature or reflux temperature does not affect the coordination number significantly. Values of 8.9 and 8.7 were obtained, respectively. No $\mathrm{Rh}-\mathrm{C}$ contributions could be fitted.

3.4.2. Estimation of particle size. Figure 9A shows the relationship between the particle size and the coordination number for spherical and semispherical particles. Because in some cases no additional rhodium atoms are included in the modelled particle upon increase of its size with $0.1 \mathrm{~nm}$, some points have the same coordination number. The data points were fitted with logarithmic functions. Figure 9B displays the relationship between the particle size and the number of atoms in the particle. The results obtained correspond well with data obtained by Kip et al. (32). The figures clearly show that the outcome depends considerably upon the assumed particle shape. However, the geometry of the $\mathrm{Rh} / \mathrm{CNF}$ particles is not known. The smallest particles could well be a semispherical shape, whereas the larger particles could adapt a more spherical shape. Therefore, the average of the particle size obtained for spherical and semispherical particles was taken. Table 4 displays the results for all

\section{TABLE 4}

Estimated Average Particle Sizes for All Catalysts

\begin{tabular}{lcc}
\hline \multicolumn{1}{c}{ Catalyst } & $N_{\mathrm{Rh}-\mathrm{Rh}}$ & $D(\mathrm{~nm})$ \\
\hline $\mathrm{Rh} / \mathrm{CNF}(\mathrm{imp}, \mathrm{c} 150, \mathrm{r} 140)$ & 5.8 & 1.1 \\
$\mathrm{Rh} / \mathrm{CNF}(\mathrm{imp}, \mathrm{c} 250, \mathrm{r} 140)$ & 5.9 & 1.1 \\
$\mathrm{Rh} / \mathrm{CNF}(\mathrm{imp}, \mathrm{r} 160)$ & 6.7 & 1.4 \\
$\mathrm{Rh} / \mathrm{CNF}(\mathrm{imp}, \mathrm{c} 150, \mathrm{r} 250)$ & 7.7 & 1.7 \\
$\mathrm{Rh} / \mathrm{CNF}(\mathrm{imp}, \mathrm{c} 250, \mathrm{r} 250)$ & 7.5 & 1.6 \\
$\mathrm{Rh} / \mathrm{CNF}(\mathrm{imp}, \mathrm{r} 250)$ & 7.8 & 1.7 \\
$\mathrm{Rh} / \mathrm{CNF}(\mathrm{IET}, \mathrm{r} 200)$ & 5.9 & 1.1 \\
$\mathrm{Rh} / \mathrm{CNF}(\mathrm{IEN}, \mathrm{r} 200)$ & 8.9 & 2.1 \\
$\mathrm{Rh} / \mathrm{CNF}(\mathrm{IENT}, \mathrm{r} 200)$ & 8.7 & 2.0 \\
\hline
\end{tabular}



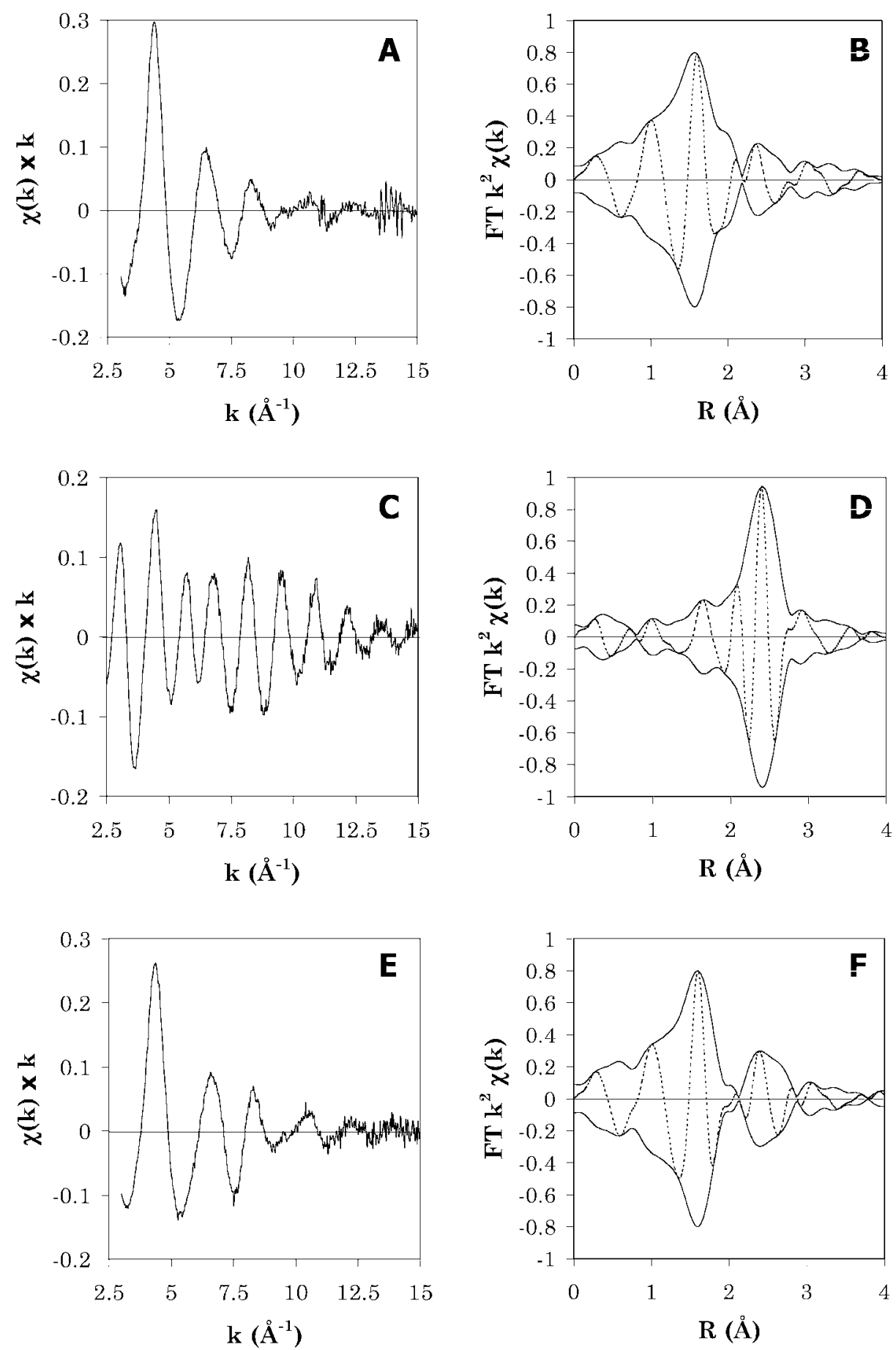

FIG. 6. Experimental $k^{1}$-weighted EXAFS spectra of $\mathrm{Rh} / \mathrm{CNF}(\mathrm{IET})(\mathrm{A}), \mathrm{Rh} / \mathrm{CNF}(\mathrm{IET}, \mathrm{r} 200)(\mathrm{C})$, and $\mathrm{Rh} / \mathrm{CNF}(\mathrm{IET}, \mathrm{rNaBH} 4)(\mathrm{E})$ and the corresponding uncorrected Fourier transforms (B, D, and F, respectively) ( $k^{2}$ weighted, $\left.\Delta k=3.9-14 \AA^{-1}\right)$.

catalysts. The size of the rhodium particles in the catalysts ranges from 1.1 to $2.1 \mathrm{~nm}$.

\subsection{Catalytic Test Experiments}

The catalytic measurements resulted in a plot of the $\mathrm{H}_{2}$ flow against time [see Fig. 10 for Rh/CNF(imp, c150, r140)].
This curve was integrated to get an $\mathrm{H}_{2}$ uptake pattern, which, in turn, was used to calculate the initial activity (i.e., the activity in mol of $\mathrm{H}_{2} / \mathrm{g}_{\text {cat }} \mathrm{h}^{-1}$ at $\left.t=0\right)$. The results are summarized in Table 5 together with the estimated particle sizes. Figure 11 shows a plot of the initial activities against the particle size. All activities could be reproduced well within $10 \%$. 

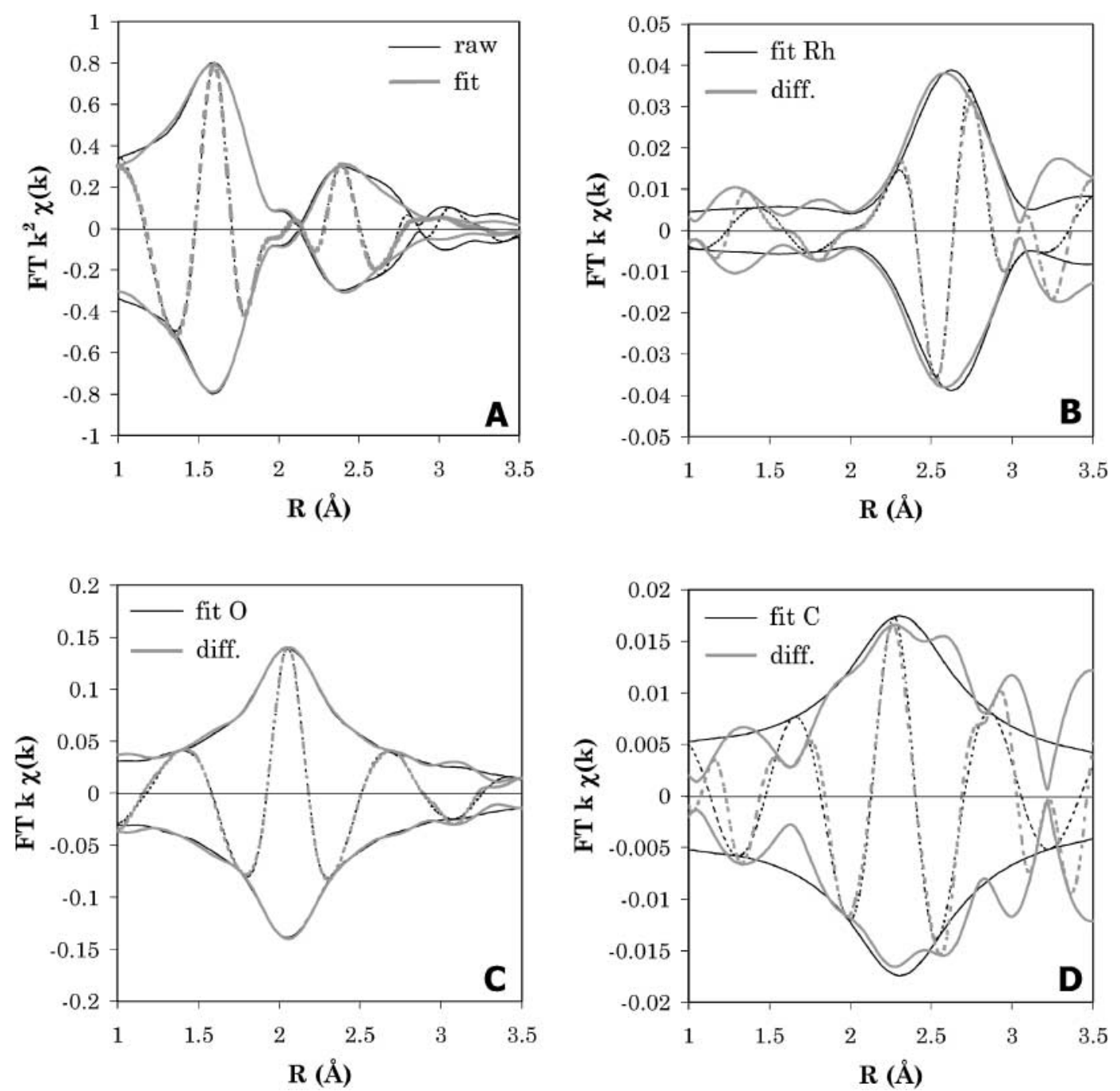

FIG. 7. Fit results of $\mathrm{Rh} / \mathrm{CNF}\left(\mathrm{IET}, \mathrm{rNaBH}_{4}\right)\left(\Delta k=3.9-14 \AA^{-1}, \Delta R=1-2.8 \AA\right)$. (A) Fourier transform of experimental EXAFS data and total fit ( $k^{2}$ weighted, uncorrected). (B) Rhodium-rhodium fit and corresponding difference file ( $k^{1}$ weighted, Rh-Rh phase corrected). (C) Rhodium-oxygen fit and corresponding difference file ( $k^{1}$ weighted, Rh-O phase corrected). (D) Rhodium-carbon fit and corresponding difference file ( $k^{1}$ weighted, $\mathrm{Rh}-\mathrm{C}$ phase corrected).

TABLE 5

Initial Activities and Estimated Particle Sizes for All Catalysts

\begin{tabular}{lcc}
\hline \multicolumn{1}{c}{ Catalyst $^{a}$} & $\begin{array}{c}\text { Initial activity } \\
\left(\mathrm{mol} \mathrm{H}_{2} / \mathrm{g}_{\text {cat }} \mathrm{h}^{-1}\right)\end{array}$ & $D(\mathrm{~nm})$ \\
\hline 1. Rh/CNF(imp, c150, r140) & 0.78 & 1.1 \\
2. Rh/CNF(imp, c250, r140) & $0.71^{b}$ & 1.1 \\
3. Rh/CNF(imp, r160) & 0.74 & 1.4 \\
4. Rh/CNF(imp, c150, r250) & 1.13 & 1.7 \\
5. Rh/CNF(imp, c250, r250) & 0.86 & 1.6 \\
6. Rh/CNF(imp, r250) & 0.83 & 1.7 \\
7. Rh/CNF(IET, r200) & 1.12 & 1.1 \\
- Rh/CNF(IET, rNaBH & -1.1 \\
8. Rh/CNF(IEN, r200) & 1.04 & 2.1 \\
9. Rh/CNF(IENT, r200) & 0.86 & 2.0 \\
\hline
\end{tabular}

${ }^{a}$ Catalyst quantity, used $50 \mathrm{mg}$.

${ }^{b}$ With $100 \mathrm{mg}$ the same value was obtained.
It is important to determine whether the measured activity is influenced by diffusion of the reactants and products to and from the active sites. In general, three mass transfer phenomena can be distinguished for the reactants in hydrogenation reactions (30): (i) transfer of hydrogen from the gas phase to the liquid phase, (ii) transport of the reactants to the external surface of the catalyst particle (external mass transfer), (iii) transport of the reactants from the external surface of the particle through the pores to the active sites on the interior surface (internal mass transfer). As was pointed out under Experimental, under the conditions used, the rate of dissolution of $\mathrm{H}_{2}$ in the solvent is higher than the maximum measurable rate of $\mathrm{H}_{2}$ uptake. In other words, the rate is independent of stirrer frequency. Stirring at a higher speed decreases the stagnant layer around a catalyst particle. In the case of external diffusion limitation, an effect of stirrer frequency on the activity should 

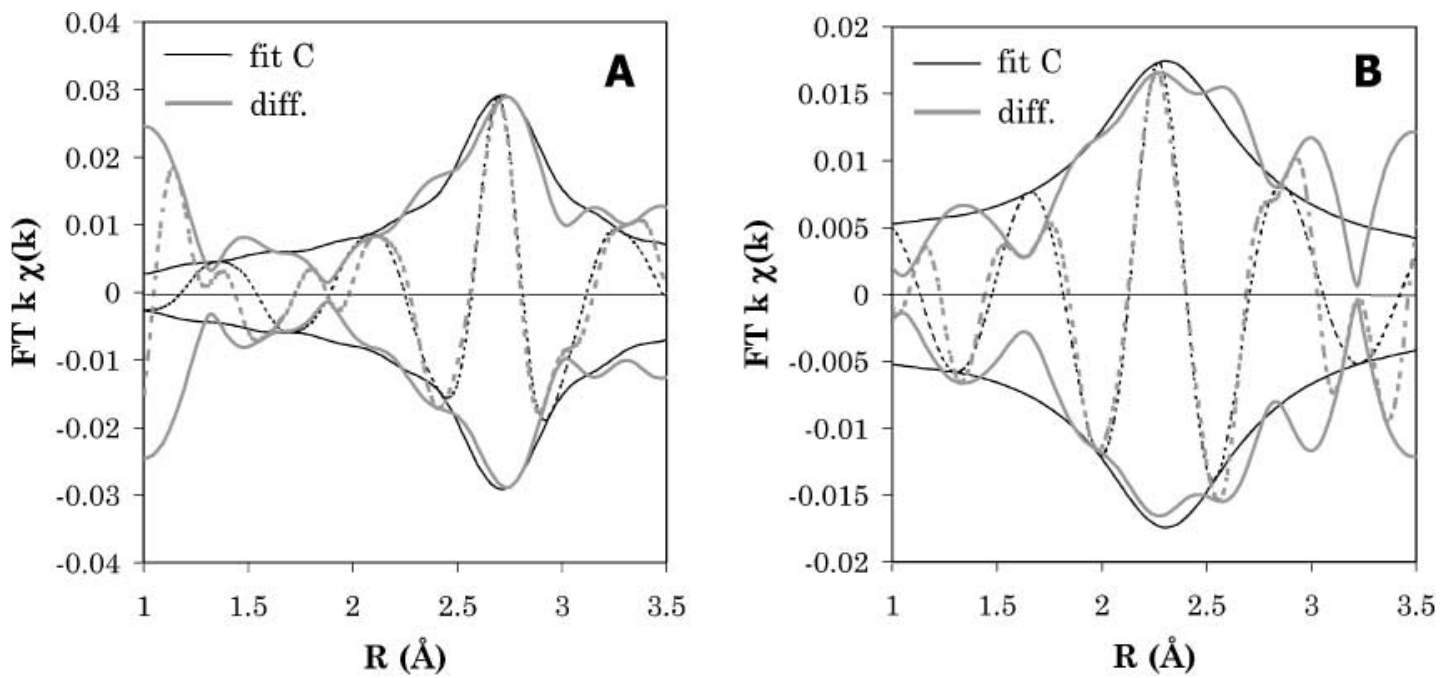

FIG. 8. Rhodium-carbon fits and corresponding difference files ( $k^{1}$ weighted, Rh-C phase corrected) of (A) $\mathrm{Rh} / \mathrm{CNF}(\mathrm{imp}, \mathrm{c} 150, \mathrm{r} 140)$ and (B) $\mathrm{Rh} / \mathrm{CNF}\left(\mathrm{IET}, \mathrm{rNaBH}_{4}\right)$.

be expected. Therefore, it is highly unlikely that the reaction rate is affected by transfer of $\mathrm{H}_{2}$ to the liquid phase or by diffusion of reactants to the external surface of the catalyst particle. What remains is the question of whether there is internal diffusion limitation or not. An easy check is to decrease the catalyst particle size. If the reaction rate is not affected by this procedure, the reaction is not limited by internal diffusion. However, the catalysts used in this study are already powdered and it is difficult to control particle size on such a small scale. Therefore, as a rough check, two catalysts $[\mathrm{Rh} / \mathrm{CNF}$ (imp, c250, r140) and Rh/CNF(imp, c250, r250)] were powdered with a mortar very thoroughly

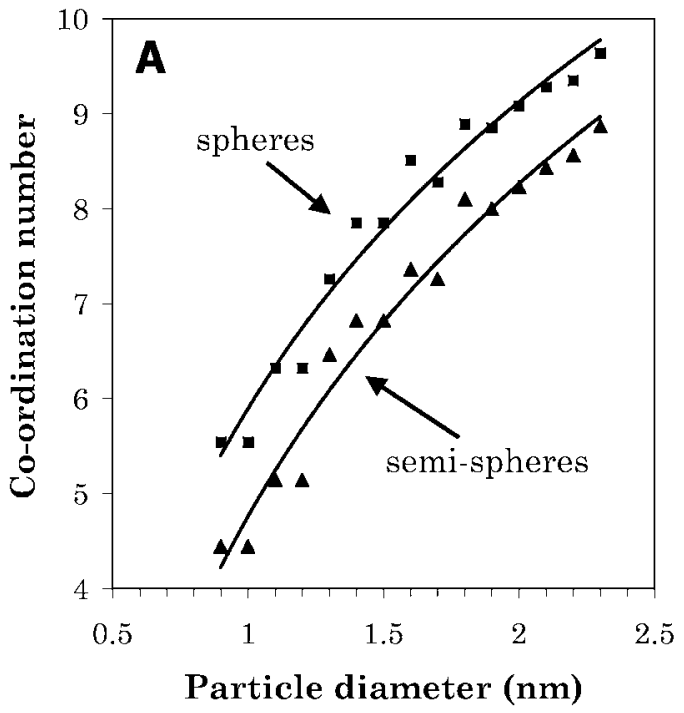

in order to decrease the particle size even further. Both catalysts showed about a threefold increase in activity. Although these results must be interpreted with care, because other factors, such as the clustering of support bodies, can also play a role when a catalyst is subjected to such mechanical forces, the outcome of this experiment points to the presence of internal diffusion limitation. To shed more light on this diffusion phenomenon the internal effectiveness factor $\eta$ was calculated. Estimations of the values of the parameters needed to calculate $\eta$ are shown in Table 6 .

It was ascertained that the reaction studied was indeed first order with respect to cyclohexene [plotting $\ln \left(\mathrm{C}_{0} / \mathrm{C}\right)$

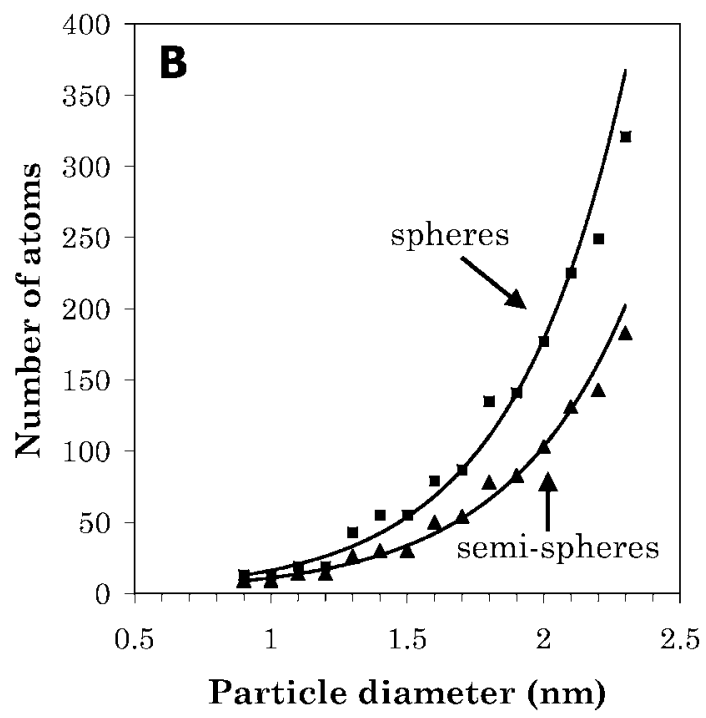

FIG. 9. (A) First shell coordination number against particle diameter for spherical and semispherical particles. (B) Number of atoms against particle diameter for spherical and semispherical particles. 

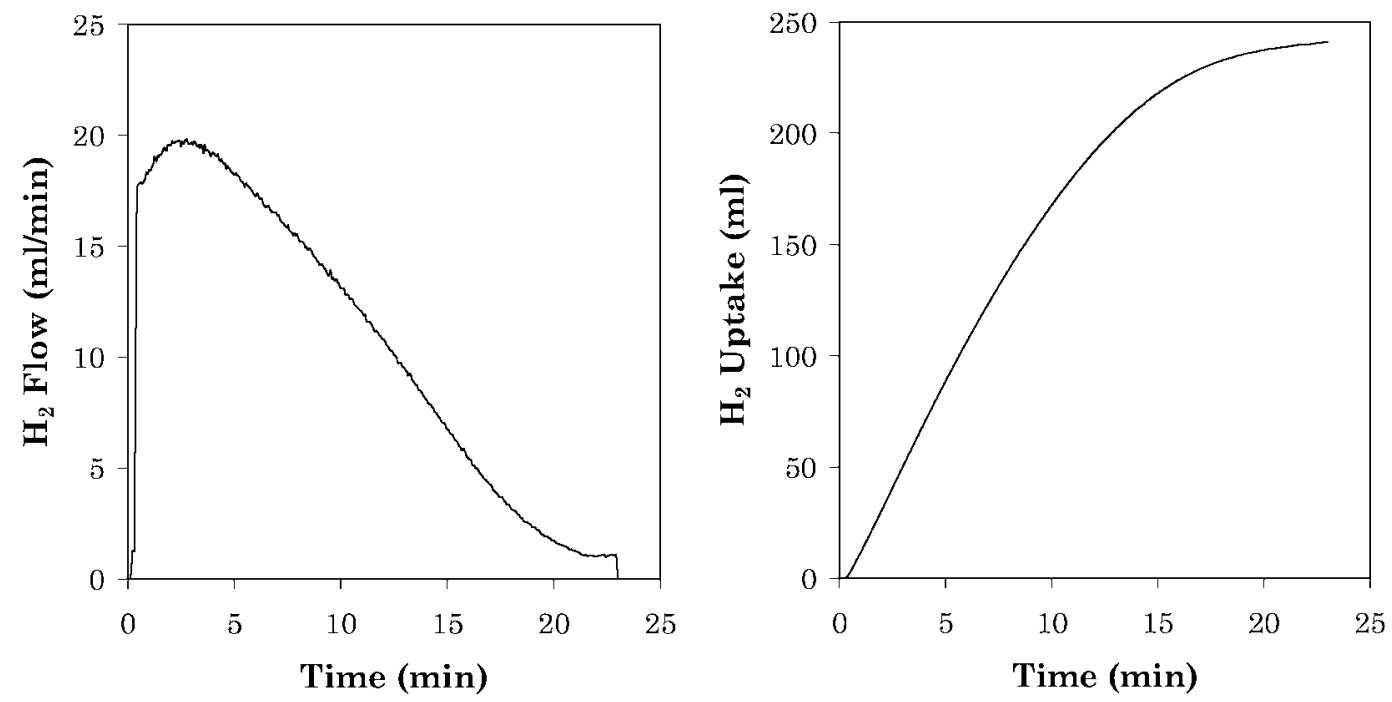

FIG. 10. $\mathrm{H}_{2}$ flow and $\mathrm{H}_{2}$ uptake curves of Rh/CNF(imp, c150, r140).

against $t$ resulted in a straight line]. Cyclohexene concentrations were calculated from the initial concentration and the $\mathrm{H}_{2}$ uptake pattern. Calculated $k_{1}$ values at all concentrations of cyclohexene during reaction with $\mathrm{Rh} / \mathrm{CNF}(\mathrm{imp}$, c250, r250) were averaged. For particles of $20 \mu \mathrm{m}$, which is a reasonable value for these catalysts (see Fig. 1A), a Thiele modulus $\varphi$ of 0.46 and an effectiveness factor $\eta$ of 0.94 is obtained. We would like to point out that the cyclic calculation referred to under Experimental did not have any significant effect on the value of $\eta$. In other words, the observed first-rate order in cyclohexene is not influenced by diffusion. This calculation also shows that it is unlikely that the reaction is limited by internal diffusion of cyclohexene. However, considering that the concentration of $\mathrm{H}_{2}$ in the bulk solution is much lower than that of cyclohexene $\left(3.5 \times 10^{-3}\right.$ (33) vs. $0.1 \mathrm{~mol} / \mathrm{L}$, respectively), the rate of the reaction is probably limited by the availability of $\mathrm{H}_{2}$. Consequently, the initial activities obtained for the Rh/CNF catalysts should only be considered qualitatively. As is shown in Eq. [6] the Thiele modulus $\varphi$ and therewith the effectiveness factor $\eta$ is still always dependent upon the reaction rate $k_{v, p}$. If we assume that the limitation with respect to $\mathrm{H}_{2}$ is about the same for all catalysts, different intrinsic activities will still lead to different observed reaction rates, although the differences would be smaller than without any diffusion limitations. It should be noted that after having powdered both catalysts severely, the catalyst Rh/CNF(imp, c250, r250) was still more active than the catalyst $\mathrm{Rh} / \mathrm{CNF}$ (imp, c250, r140).

\section{TABLE 6}

Values of the Parameters Needed to Calculate the Internal Effectiveness Factor $\eta$ for Cyclohexene (see Eqs. [5]-[9])

\begin{tabular}{ll}
\hline \multicolumn{1}{c}{ Parameter } & \multicolumn{1}{c}{ Value } \\
\hline$d_{p}$ & $2 \times 10^{-5} \mathrm{~m}$ \\
$D_{A}{ }^{a}$ & $10^{-9} \mathrm{~m}^{2} \mathrm{~s}^{-1}$ \\
Total pore volume $^{b}$ & $0.4 \mathrm{ml} \mathrm{g}^{-1}$ \\
$\rho_{\text {fibres }}{ }^{c}$ & $2.25 \times 10^{-3} \mathrm{~kg} \mathrm{~m}^{-3}$ \\
$\varepsilon_{p}$ & 0.47 \\
$\tau$ & 2 \\
$D_{e A}$ & $2.4 \times 10^{-10} \mathrm{~m}^{2} \mathrm{~s}^{-1}$ \\
$k_{1}{ }^{d}$ & $1.7 \times 10^{-3} \mathrm{~s}^{-1}$ \\
$k_{v, p}$ & $4.1 \mathrm{~s}^{-1}$ \\
$\varphi$ & 0.46 \\
$\eta$ & 0.94
\end{tabular}

\footnotetext{
${ }^{a}$ Typical for liquid phase.

${ }^{b}$ See Experimental section.

${ }^{c} \rho_{\text {graphite }} \cong \rho_{\text {fibres }}(34)$.

${ }^{d}$ Averaged over all cyclohexene concentrations during reaction.
}

FIG. 11. Initial activity against particle diameter for all catalysts. 
This supports the assumption that the observed activities are related to intrinsic activities.

Table 5 and Figure 11 show that not much effect of rhodium metal particle size on the catalytic activity is observed. With the exception of $\mathrm{Rh} / \mathrm{CNF}$ (imp, c150, r250) and $\mathrm{Rh} / \mathrm{CNF}(\mathrm{IET}, \mathrm{r} 200)$ all catalysts exhibit about the same activity.

\section{DISCUSSION}

\subsection{Pretreatment of Carbon Nanofibres}

The TEM results have shown that after impregnation with an aqueous solution of $\mathrm{RhCl}_{3} \cdot 2 \mathrm{H}_{2} \mathrm{O}$, small rhodium metal particles are deposited only on carbon nanofibres that are surface oxidized with $\mathrm{HNO}_{3} / \mathrm{H}_{2} \mathrm{SO}_{4}$. These findings can be explained by taking into account the wetting properties of the differently treated fibres. It has been shown before (31) that untreated fibres do not show any affinity for water. Fibres treated with $\mathrm{HNO}_{3}$ have some affinity for water, whereas only $\mathrm{HNO}_{3} / \mathrm{H}_{2} \mathrm{SO}_{4}$-oxidized fibres are well wetted by this solvent. Consequently, dissolved $\mathrm{RhCl}_{3} \cdot 2 \mathrm{H}_{2} \mathrm{O}$ can only reach the surface of the $\mathrm{HNO}_{3} / \mathrm{H}_{2} \mathrm{SO}_{4}$-oxidized CNFs. With the untreated fibres the rhodium particles are mainly deposited on or near the $\mathrm{Al}_{2} \mathrm{O}_{3}$ particles that are still present and are deposited as some large metal lumps. The affinity of the particles for $\mathrm{Al}_{2} \mathrm{O}_{3}$ is also not very large, because ultrasonic treatment during the TEM sample preparation dispatches the particles from the $\mathrm{Al}_{2} \mathrm{O}_{3}$ support (see Fig. 2B). With the $\mathrm{HNO}_{3}$ oxidized fibres about $50 \%$ of the original amount of $\mathrm{Al}_{2} \mathrm{O}_{3}$ is removed during the oxidation treatment (31), decreasing the chance that the $\mathrm{Rh}$ will be deposited on or near this oxidic carrier. Furthermore, the fibres have developed some affinity for water. This results in large rhodium particles between the fibres. Prinsloo obtained similar results with the impregnation of an iron precursor onto $\mathrm{HNO}_{3}$ oxidized CNFs (35). The $\mathrm{Al}_{2} \mathrm{O}_{3}$ within the skeins of fibre that were treated with $\mathrm{HNO}_{3} / \mathrm{H}_{2} \mathrm{SO}_{4}$ is removed by about $80 \%$ (31). Furthermore, the remaining $\mathrm{Al}_{2} \mathrm{O}_{3}$ is most probably $\alpha-\mathrm{Al}_{2} \mathrm{O}_{3}$ of a low surface area, present in the highsurface-area $\gamma-\mathrm{Al}_{2} \mathrm{O}_{3}$ used for the synthesis of the carbon nanofibres. Therefore, not much influence of the remaining alumina on the formation of $\mathrm{Rh}$ particles on the carbon nanofibres is to be expected. The $\mathrm{HNO}_{3} / \mathrm{H}_{2} \mathrm{SO}_{4}$-oxidized fibres are nicely wetted with water and small rhodium particles are formed after reduction. In view of the abovedescribed results, the research was continued with only the $\mathrm{HNO}_{3} / \mathrm{H}_{2} \mathrm{SO}_{4}$-oxidized impregnated catalysts.

The TEM results demonstrate that the wetting properties of the carbon nanofibres are crucial for success of the impregnation. Furthermore, quite a large influence of the remaining $\mathrm{Al}_{2} \mathrm{O}_{3}$ has been observed. Only after the severe oxidation treatment does alumina largely dissolve in the strong acid. These results call for the growth of carbon nanofibres from a growth catalyst with an easily removable support, such as silica. Growth from a Ni/C support would be another option, since the carbon would not pollute the fibres. It would then become possible to obtain pure untreated fibres, which could be impregnated with an organic solution. This could be another interesting method of synthesis of metal particles on CNFs.

\subsection{Preparation of Small Rhodium Particles on Surface-Oxidized Carbon Nanofibres}

The EXAFS results have shown that with all catalysts very small rhodium particles have been formed on the fishbone carbon nanofibres. With $\mathrm{Rh} / \mathrm{CNF}\left(\mathrm{IET}, \mathrm{rNaBH}_{4}\right)$ no particle size could be estimated based on the Rh-Rh coordination number, because the particles are partly oxidized. The reduction procedure with $\mathrm{NaBH}_{4}$ was executed ex situ and the catalyst was exposed to air afterwards. Most probably, the particles consist of a rhodium metal core surrounded by an oxidic phase. We roughly estimate that the particle size ranges between 1.5 and $2 \mathrm{~nm}$. A larger diameter is not likely, because a $\mathrm{Rh}-\mathrm{C}$ contribution is still observed.

With the impregnated catalysts the particle size ranges from 1.1 to $1.7 \mathrm{~nm}$. The results obtained with the lowtemperature reductions, i.e., $140-160^{\circ} \mathrm{C}$, have shown that calcination at 150 or $250^{\circ} \mathrm{C}$ makes no difference for the particle size obtained. However, direct reduction results in larger particles. This difference can be explained by higher mobility of rhodium chloride under reducing than under oxidising conditions. Furthermore, the reduction temperature of the direct reduction is $20^{\circ} \mathrm{C}$ higher than that of the reduction after calcination. The EXAFS results show that the particles are completely reduced after reduction at $140-160^{\circ} \mathrm{C}$. No Rh-O contributions could be fitted in the spectrum. This result agrees well with the profiles obtained during temperature-programmed reduction. Furthermore, no chlorine is present in the coordination sphere of the rhodium, although it is still possible that chlorine is present near the rhodium particle. When the catalysts are reduced at $250^{\circ} \mathrm{C}$, no differences in particle size are observed anymore. It is, therefore, likely that at this temperature the mobility of the rhodium metal atoms and not the rhodium chloride is decisive for the final size of the particles.

With the ion-exchanged catalysts, stirring at room temperature with an aqueous solution of $\mathrm{RhCl}_{3} \cdot 2 \mathrm{H}_{2} \mathrm{O}$ was not successful. This result can be explained by the relatively high acidity of this solution. The solution of $3.7 \times 10^{-3} \mathrm{~mol} / \mathrm{L}$ used had a $\mathrm{pH}$ of 2.9. Hoogenraad and co-workers (4) found that the isoelectric point of $\mathrm{HNO}_{3}$-oxidized fibres is about 2.3. At $\mathrm{pH}$ values above this point the fibres are negatively charged. The $\mathrm{pH}$ of the solution used for ion exchange was, therefore, probably very close to the isoelectric point of the fibres and there would have been barely any driving force for ion exchange. Furthermore, the structure and, therefore, the charge of $\mathrm{RhCl}_{3} \cdot 2 \mathrm{H}_{2} \mathrm{O}$ in water was uncertain. 
Complexes such as $\left[\mathrm{Rh}\left(\mathrm{H}_{2} \mathrm{O}\right)_{6}\right]^{3+},\left[\mathrm{Rh}(\mathrm{OH})_{3} \mathrm{Cl}_{3}\right]^{3-}$, or $\left[\mathrm{RhCl}_{6}\right]^{3-}$ may have been present in solution (36).

When an aqueous solution of $\mathrm{RhCl}_{3} \cdot 2 \mathrm{H}_{2} \mathrm{O}$ is refluxed with the oxidized fibres, on the other hand, a rhodium complex is formed on the CNFs [see EXAFS data of $\mathrm{Rh} / \mathrm{CNF}(\mathrm{IET})]$. The synthesis procedure resembles that of procedures used with rhodium complex chemistry (37, $38)$. It is, therefore, likely that rhodium has formed a complex with the carboxyl groups on the surface of the fibres. The negatively charged $\mathrm{COO}^{-}$group and the two chloride ions compensate for the charge of the $\mathrm{Rh}(\mathrm{III})$ ion. Three water molecules probably complete the coordination sphere of the central rhodium ion. Subsequent reduction with $\mathrm{H}_{2}$ at $200^{\circ} \mathrm{C}$ gives extremely small rhodium particles, $1.1 \mathrm{~nm}$ in size. By optimization of the reduction procedure it is probably possible to synthesize even smaller particles using this approach. Reduction with $\mathrm{NaBH}_{4}$ gives larger particles, $1.5-2 \mathrm{~nm}$ in size. Probably this is due to the relatively rough method of reduction [all $\mathrm{NaBH}_{4}$ was added at once to the fibres that were (badly) stirred in a roundbottomed flask].

Another successful ion exchange procedure involved addition of $\mathrm{NH}_{3}$ to the aqueous solution of $\mathrm{RhCl}_{3} \cdot 2 \mathrm{H}_{2} \mathrm{O}$. Two factors play a role with this procedure: (i) the $\mathrm{pH}$ of the solution is raised, increasing the driving force of ion exchange between the negatively charged CNF surface and a positively charged complex, and (ii) most probably the positively charged $\left[\mathrm{Rh}\left(\mathrm{NH}_{3}\right)_{5} \mathrm{Cl}\right]^{2+}$ complex is formed $(39,40)$. No effect of an increase of temperature during ion exchange on the final size of the rhodium particles was found using this synthesis procedure. However, the metal particles formed using this ion-exchange method are much larger than with other catalyst preparation techniques. This is probably due to the high mobility of metal ammine complexes under reducing atmospheres $(41,42)$. Careful drying and calcination procedures could decrease the particle size obtained considerably.

The particle sizes obtained with the synthesis of the $1 \mathrm{wt} \%$ rhodium-on-fishbone carbon nanofibre catalysts are very small compared to results reported in the literature. Deposition of rhodium on carbon nanofibres or nanotubes has not been reported yet, but for other metals several reports exist. Hoogenraad and co-workers (6) synthesized $\mathrm{Pd}$ on $\mathrm{HNO}_{3}$-oxidized parallel CNFs using ion exchange of $\left[\mathrm{Pd}\left(\mathrm{NH}_{3}\right)_{4}\right]\left(\mathrm{NO}_{3}\right)_{2}$ and subsequent reduction at $200^{\circ} \mathrm{C}$. They obtained an EXAFS coordination number of 7.9 and estimated the size of the particles to be $1.5 \mathrm{~nm}$. Ang et al. (14) obtained $\mathrm{Pd}$ particles $2 \mathrm{~nm}$ in size on $\mathrm{HNO}_{3} / \mathrm{H}_{2} \mathrm{SO}_{4}$ oxidized carbon nanotubes by electroless plating. Ledoux and co-workers (12) impregnated palladium nitrate on CNFs and observed 3- to 5-nm particles, while Planeix et al. (13) prepared 3- to 7-nm Ru particles on carbon nanotubes. Finally, Park and Baker (9) impregnated a solution of nickel nitrate in ethanol on CNFs and detected particles of an av- erage diameter of 6-8 nm. The results of this work demonstrate that it is possible to synthesize very small metal particles on oxidized CNFs. With particles of 1-2 nm the precious metal component of the catalyst will be optimally used. In other words, almost all metal atoms are surface atoms. Furthermore, with particles of this size, metalsupport interactions can be studied. Several researchers found increased activities or selectivities when carbon nanofibres or nanotubes were used as the support (7-13). More information about the interaction between the metal and the CNF support could shed some light on these phenomena.

\subsection{Metal-Support Interaction in $R h / C N F s$}

The size of the particles obtained is so small that the metal-support contact can be observed. With the exception of $\mathrm{Rh} / \mathrm{CNF}$ (IEN, r200) and Rh/CNF(IENT, r200) all catalysts show a $\mathrm{Rh}-\mathrm{C}$ contribution. The size of the particles in $\mathrm{Rh} / \mathrm{CNF}(\mathrm{IEN}, \mathrm{r} 200)$ and $\mathrm{Rh} / \mathrm{CNF}(\mathrm{IENT}, \mathrm{r} 200)$ is too large to observe this contribution. An interesting observation can be made by comparison of a catalyst that is reduced with $\mathrm{H}_{2}$ [Rh/CNF(imp, c150, r140)] and the $\mathrm{NaBH}_{4}$-reduced catalyst $\left[\mathrm{Rh} / \mathrm{CNF}\left(\mathrm{IET}, \mathrm{rNaBH}_{4}\right)\right]$. Upon reduction with $\mathrm{H}_{2}$ the $\mathrm{Rh}-\mathrm{C}$ distance is observed at $2.70 \AA$, whereas after reduction with $\mathrm{NaBH}_{4}$ this distance is evident at $2.29 \AA$. This difference can be explained by assuming the presence of hydrogen at the interface of the rhodium metal particle and the carbon nanofibre support with the $\mathrm{H}_{2}$-reduced catalyst. A schematic depiction of rhodium particles on carbon nanofibres in $\mathrm{Rh} / \mathrm{CNF}(\mathrm{imp}, \mathrm{c} 150, \mathrm{r} 140)$ and $\mathrm{Rh} / \mathrm{CNF}$ (IET, $\left.\mathrm{rNaBH}_{4}\right)$ is shown in Fig. 12. As a rhodium-carbon contribution is observed it is likely that the particle has a large interface area with the support. A semispherical shape could then be assumed. With Rh/CNF(imp, c150, r140) the rhodium particle is fully metallic. In between the particle and the carbon nanofibre support interface hydrogen is situated, creating a large $\mathrm{Rh}-\mathrm{C}$ distance. With $\mathrm{Rh} / \mathrm{CNF}$ (IET, $\mathrm{rNaBH}_{4}$ ) the rhodium particle is partly oxidized. A rhodium core is surrounded by an oxidic phase. In this case, no interface hydrogen is present and the $\mathrm{Rh}-\mathrm{C}$ distance is short.

The phenomenon of interface hydrogen has repeatedly been observed with several metals, such as Rh, Ir,
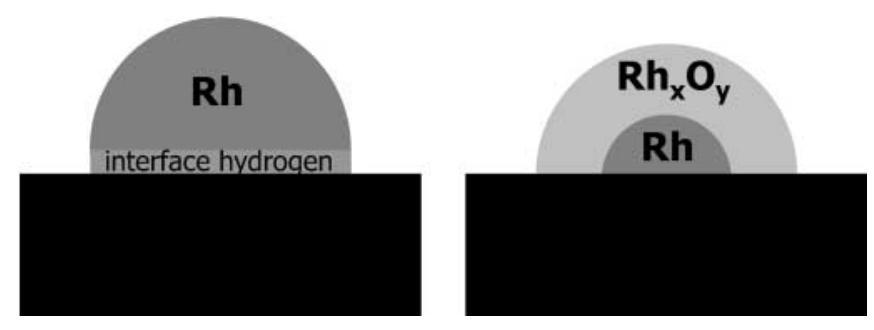

FIG. 12. Schematic depiction of rhodium particles on carbon nanofibres in $\mathrm{Rh} / \mathrm{CNF}\left(\mathrm{imp}, \mathrm{c} 150, \mathrm{r} 140\right.$ ) (left) and $\mathrm{Rh} / \mathrm{CNF}\left(\mathrm{IET}, \mathrm{rNaBH}_{4}\right)$ (right). 
and $\mathrm{Pt}$, on oxidic carriers $\left(\gamma-\mathrm{Al}_{2} \mathrm{O}_{3}, \mathrm{TiO}_{2}\right.$, zeolite-Y) by Koningsberger and co-workers (43-46). Reduction of the catalysts at low temperature, i.e., below $300^{\circ} \mathrm{C}$, results in a long metal-oxygen distance, about 2.6-2.7 $\AA$. Upon subsequent evacuation at $200^{\circ} \mathrm{C}$ the $M-\mathrm{O}$ distance contracts to about 2.1-2.2 A. Ensuing reduction restores the long $M-\mathrm{O}$ interaction. These results clearly show that the occurrence of the long $M-\mathrm{O}$ interaction is associated with hydrogen and that the presence of interface hydrogen is a likely explanation for the above-described observations. With the $\mathrm{Rh} / \mathrm{CNF}$ catalysts the difference in $\mathrm{Rh}-\mathrm{C}$ distance can explained by the different reducing agents used. Whereas reduction with $\mathrm{H}_{2}$ results in a long $\mathrm{Rh}-\mathrm{C}$ distance, in accordance with earlier observations, reduction with $\mathrm{NaBH}_{4}$ gives a short $\mathrm{Rh}-\mathrm{C}$ distance, because the catalyst does not come into contact with molecular hydrogen. Thus, reduction with $\mathrm{NaBH}_{4}$ can be compared to evacuation of the catalyst at elevated temperature.

\subsection{Catalytic Test Experiments}

The presence of internal diffusion limitations with respect to $\mathrm{H}_{2}$ during the hydrogenation of cyclohexene with the $\mathrm{Rh} / \mathrm{CNF}$ catalysts is remarkable. With liquid-phase reactions external diffusion limitations would rather be expected to take place, because the stagnant layer around the catalyst particle is large compared to the size of the particle. Furthermore, the carbon nanofibres have a mesoporous macrostructure, the loading of active metal component is low $(1 \mathrm{wt} \%)$, and the concentration of cyclohexene is only $1 \% \mathrm{v} / \mathrm{v}$. However, the reaction is executed at a $\mathrm{H}_{2}$ pressure of only 1200 mbar and the catalysts turn out to be extremely active in this test reaction. A simple solution would be to increase the hydrogen pressure in order to increase the solubility of this gas in the solvent. Unfortunately, this remedy was not possible with our experimental setup.

As was pointed out above, the activities of the catalysts still qualitatively reflect the intrinsic activities. Figure 11 shows that, with the exception of Rh/CNF(imp, c150, r250) and $\mathrm{Rh} / \mathrm{CNF}(\mathrm{IET}, \mathrm{r} 200)$, no effect of rhodium metal particle size on catalytic activity is observed. As the rhodium metal surface area decreases with increasing particle size, this means that the turnover frequency (TOF) would increase significantly with the rhodium particle size. The lack of effect of the particle size on the catalytic activity is quite surprising, as cyclohexene hydrogenation is generally reported to be a structure-insensitive reaction. With a structureinsensitive reaction a decrease of activity should be found with increasing particle size. Boudart and co-workers, for instance, found that the liquid-phase hydrogenation of cyclohexene was independent of particle size for $\mathrm{Rh} / \mathrm{Al}_{2} \mathrm{O}_{3}$ (49), $\mathrm{Pd} / \mathrm{SiO}_{2}$ and $\mathrm{Pd} / \mathrm{Al}_{2} \mathrm{O}_{3}(50)$, and $\mathrm{Ni} / \mathrm{SiO}_{2}$ (51) catalysts. However, Jackson and co-workers (52) did find a dependence of metal crystallite size on the activity in cyclohexene hydrogenation for Pd on alumina, carbon, silica, and zirconia. An optimum size of about $3 \mathrm{~nm}$ was found. This behavior they related to the strength and mode of adsorption of cyclohexene, although the adsorption characteristics of $\mathrm{H}_{2}$ could play a role as well. The same conclusion was drawn by Busser et al. (53), who, surprisingly, found a decrease in TOF with increasing particle size for polymerstabilized rhodium colloids. Augustine et al. (54) reported that with Pt catalysts several alkene hydrogenation sites exist that are related to the mode of adsorption of hydrogen. Müller et al. (55) showed that the adsorption and desorption as well as the Faradaic hydrogenation of cyclohexene are structure sensitive. The rate of hydrogenation was higher on $\operatorname{Pt}(110)$ or roughened surfaces.

The results reported in this work, however, indicate that the effect of metal particle size on the activity in the liquidphase hydrogenation of cyclohexene is low. In our opinion, other effects, such as the clustering of the support bodies in the liquid phase, the effect of water present in the system, and the influence of oxygen-containing groups of the surface, are much more important. It should be stressed that all activities obtained in this study could be reproduced well within $10 \%$. The high activities of $\mathrm{Rh} / \mathrm{CNF}$ (imp, c150, r250) and $\mathrm{Rh} / \mathrm{CNF}(\mathrm{IET}, \mathrm{r} 200)$ are striking and reflect the fact that many more factors than just metal particle size play a role in liquid-phase reactions. As yet we do not have enough knowledge about the system under investigation to give a conclusive explanation.

\section{CONCLUSIONS}

This study describes the synthesis of very small rhodium metal particles on $\mathrm{HNO}_{3} / \mathrm{H}_{2} \mathrm{SO}_{4}$-oxidized fishbone carbon nanofibres using several methods. The surface oxidation with $\mathrm{HNO}_{3} / \mathrm{H}_{2} \mathrm{SO}_{4}$ is a prerequisite for a good interaction between aqueous catalyst precursor solutions and the CNFs. Particle sizes ranging from 1.1 to $2.1 \mathrm{~nm}$ are obtained with $1 \mathrm{wt} \% \mathrm{Rh}$ metal loadings. The smallest rhodium particles result from impregnation, subsequent calcination at $150^{\circ} \mathrm{C}$, and reduction at $140^{\circ} \mathrm{C}$ or from ion exchange at elevated temperature with an aqueous solution of $\mathrm{RhCl}_{3} \cdot 2 \mathrm{H}_{2} \mathrm{O}$ and reduction at $200^{\circ} \mathrm{C}$. The size of the particles makes investigation of the metal-support interaction on carbon nanofibres possible. All catalysts are very active in the hydrogenation of cyclohexene. Not much effect of the metal particle size on the catalytic acitivity is observed, suggesting that other parameters, such as the clustering of support bodies in the liquid phase, are more important.

\section{ACKNOWLEDGMENTS}

We thank the HASYLAB (Hamburg, Germany) for the opportunity to perform EXAFS measurements at beamline station X1.1. We are grateful for the collection of the EXAFS data by the EXAFS measurement team. This work was supported by the Netherlands' Organisation for Scientific Research (NWO). 


\section{REFERENCES}

1. de Jong, K. P., and Geus, J. W., Catal. Rev.-Sci. Eng. 42, 481 (2000).

2. Hoogenraad, M. S., Ph.D. thesis. Utrecht University, Utrecht, The Netherlands, 1995.

3. Hoogenraad, M. S., Onwezen, M. F., van Dillen, A. J., and Geus, J. W., Stud. Surf. Sci. Catal. 101, 1331 (1995).

4. Geus, J. W., Hoogenraad, M. S., and van Dillen, A. J., in "Synthesis and Properties of Advanced Catalytic Materials" (E. Iglesia, P. W. Lednor, D. A. Nagaki, and L. T. Thompson, Eds.), p. 87. Materials Res. Soc., Pittsburgh, 1995.

5. Hoogenraad, M. S., van Leeuwarden, R. A. G. M. M., van Breda Vriesman, G. J. B., Broersma, A., van Dillen, A. J., and Geus, J. W., in "Preparation of Catalysts VI" (G. Poncelet, et al., Eds.), p. 263. Elsevier, Amsterdam, 1995.

6. Mojet, B. L., Hoogenraad, M. S., van Dillen, A. J., Geus, J. W., and Koningsberger, D. C., J. Chem. Soc. Faraday Trans. 93, 4371 (1997).

7. Rodriguez, N. M., Kim, M.-S., and Baker, R. T. K., J. Phys. Chem. 98, 13108 (1994).

8. Chambers, A., Nemes, T., Rodriguez, N. M., and Baker, R. T. K., J. Phys. Chem. B 102, 2251 (1998).

9. Park, C., and Baker, R. T. K., J. Phys. Chem. B 102, 5168 (1998).

10. Park, C., and Baker, R. T. K., J. Phys. Chem. B 103, 2453 (1999).

11. Salman, F., Park, C., and Baker, R. T. K., Catal. Today 53, 385 (1999).

12. Pham-Huu, C., Keller, N., Charbonniere, L. J., Ziessel, R., and Ledoux, M. J., Chem. Commun. 1871 (2000).

13. Planeix, J. M., Coustel, N., Coq, B., Brotons, V., Kumbhar, P. S., Dutartre, R., Geneste, P., Bernier, P., and Ajayan, P. M., J. Am. Chem. Soc. 116, 7935 (1994).

14. Ang, L.-M., Andy Hor, T. S., Xu, G.-Q., Tung, C.-H., Zhao, S., and Wang, J. L. S., Chem. Mater. 11, 2115 (1999).

15. Keyser, M., and Prinsloo, F. F., submitted for publication.

16. Teunissen, W., Ph.D. thesis. Utrecht University, Utrecht, The Netherlands, 2000.

17. Geus, J. W., Stud. Surf. Sci. Catal. 16, 1 (1983).

18. Ros, T. G., van Dillen, A. J., Geus, J. W., and Koningsberger, D. C., Chem. Phys. Phys. Chem. 3, 209 (2002).

19. Vaarkamp, M., Mojet, B. L., Modica, F. S., Miller, J. T., and Koningsberger, D. C., J. Phys. Chem. 99, 16067 (1995).

20. Vaarkamp, M., et al., http://www.xsi.nl.

21. Vaarkamp, M., Dring, I., Oldman, R. J., Stern, E. A., and Koningberger, D. C., Phys. Rev. B 50, 7872 (1994).

22. Cook, J. W., Jr., and Sayers, D. E., J. Appl. Phys. 52, 5024 (1981).

23. Koningsberger, D. C., Mojet, B. L., van Dorssen, G. E., and Ramaker, D. E., Top. Catal. 10, 143 (2000).

24. Teo, B. K., and Lee, P. A., J. Am. Chem. Soc. 101, 2815 (1979).

25. Wyckhoff, R. W. G., "Crystal Structures," Vol. 1, 2nd ed. Wiley, New York, 1963.

26. Coey, J. M. D., Acta Crystallogr. Sect. B 26, 1876 (1970).

27. Koningsberger, D. C., Jpn. J. Appl. Phys. 32, 877 (1993).

28. Stern, E. A., Phys. Rev. B 48, 9825 (1993).

29. Voogt, E. H., "THEBE, BOLLIE and NUBIE Computer Program." Surface Science Div., Debye Inst., Utrecht Univ., Utrecht, The Netherlands, 1996.
30. Kapteijn, F., Marin, G. B., and Moulijn, J. A., in "Catalysis-An Integrated Approach to Homogeneous, Heterogeneous, and Industrial Catalysis" (J. A. Moulijn, P. W. N. M. van Leeuwen, and R. A. van Santen, Eds.), p. 251. Elsevier, Amsterdam, 1993.

31. Ros, T. G., van Dillen, A. J., Geus, J. W., and Koningsberger, D. C., Chem. Eur. J. 8, 1151 (2002).

32. Kip, B. J., Duivenvoorden, F. B. M., Koningsberger, D. C., and Prins, R., J. Catal. 105, 26 (1987).

33. Young, C. L., "Hydrogen and Deuterium," Solubility Data Series, Vol. 5/6. Pergamon, Oxford, 1981.

34. Fenelonov, V. B., Avdeeva, L. B., Zheivot, V. I., Okkel', L. G., Goncharova, O. V., and Pimneva, L. G., Kinet. Catal. 34, 483 (1993).

35. Prinsloo, F. F., M. Sc. thesis. University of Cape Town, South Afrika, 2000.

36. Meyer, R. J., and Pietsch, E., "Gmelins Handbuch der Anorganischen Chemie: Ruthenium/Rhodium," 8th ed. Verlag Chemie G. M. B. H., Berlin, 1938.

37. Bukanova, A. E., Prokof'eva, I. V., and Shubochkin, L. K., Russ. J. Inorg. Chem. 25, 875 (1980).

38. Frye, H., Luschak, C., and Chinn, D., Z. Naturforsch. B 22, 268 (1967).

39. See Ref. 36.

40. Bramley, R., Figgis, B. N., and Nyholm, R. S., J. Chem. Soc. A 861 (1967).

41. Dalla Batta, R. A., and Boudart, M., in "Proceedings, 5th International Congress on Catalysis, Palm Beach, 1972" (J. W. Hightower, Ed.), p. 1329. North Holland, Amsterdam, 1973.

42. Zou, W., and Gonzales, R. D., J. Catal. 133, 202 (1992).

43. van Zon, J. B. A. D., Koningsberger, D. C., van't Blik, H. F. J., and Sayers, D. E., J. Chem. Phys. 82, 5742 (1986).

44. Koningsberger, D. C., Martens, J. H. A., Prins, R., Short, D. R., and Sayers, D. E., J. Phys. Chem. 90, 3047 (1986).

45. Vaarkamp, M., Modica, F. S., Miller, J. T., and Koningsberger, D. C., J. Catal. 163, 294 (1996).

46. Koningsberger, D. C., van Zon, F. B. M., Vaarkamp, M., and Muñoz-Paez, A., in "X-Ray Absorption Fine Structure for Catalysts and Surfaces" (Y. Iwasawa, Ed.), Series on Synchrotron Radiation Techniques and Applications, Vol. 2, p. 257. World Scientific, Singapore, 1996.

47. van Dorssen, G. E., Ph.D. thesis. Utrecht University, Utrecht, The Netherlands, 1999.

48. Koningsberger, D. C., de Graaf, J., Mojet, B. L., Ramaker, D. E., and Miller, J. T., Appl. Catal. A 191, 205 (2000).

49. Boudart, M., and Sajkowski, D. J., Faraday Discuss. 92, 57 (1991).

50. Gonzo, E. E., and Boudart, M., J. Catal. 52, 462 (1978).

51. Boudart, M., and Cheng, W.-C., J. Catal. 106, 134 (1987).

52. Jackson, S. D., Kelly, G. J., Watson, S. R., and Gulickx, R., Appl. Catal. A 187, 161 (1999).

53. Busser, G. W., van Ommen, J. G., and Lercher, J. A., Adv. Catal. Nanostruct. Mater. 213 (1996).

54. Augustine, R. L., Thompson, M. M., and Doran, M. A., J. Chem. Soc. Chem. Commun. 1173 (1987).

55. Müller, U., Schmiemann, U., Dülberg, A., and Baltruschat, H., Surf. Sci. 335, 333 (1995). 